\title{
El derecho administrativo ante la jurisprudencia de la Corte Suprema, III: Líneas y vacilaciones durante 2020 en veinte temas de la disciplina
}

Alejandro Vergara Blanco*

Este texto es la continuación de trabajos anteriores sobre las líneas y vacilaciones de la jurisprudencia de la Corte Suprema en veinte temas relevantes de la praxis de derecho administrativo, el que ahora se actualiza para el año calendario 2020. Sintetiza y grafica el resultado de una investigación de un caudal de 329 sentencias de la Corte Suprema del año señalado. Su formato es sintético. Respecto de cada tema se señala: los hechos que dan origen a la conflictividad; la ratio iuris decidendi; gráficos en que queda en evidencia la conducta lineal o zigzagueante tanto de la Sala como de sus ministros y abogados integrantes; un análisis de tal comportamiento; $y$, un recuento exhaustivo de sentencias. El resultado es distinto al del primer y segundo estudio: si bien persisten algunas vacilaciones de la Corte Suprema, durante 2020 existe un aumento de temas con jurisprudencia uniforme. No obstante que se mantiene alguna conducta errática de algunos de sus ministros y abogados integrantes.
This text is the continuation of previous works on the lines and vacillations of the jurisprudence of the Supreme Court in twenty relevant issues of the praxis of administrative law; which is now updated for the 2020 calendar year. It synthesizes and graphs the result of an investigation of a volume of 329 Supreme Court judgments of the year 2020. Its format is synthetic. Regarding each issue, it is indicated: the facts that originated the conflict; the ratio iuris decidendi; graphics that evidences the linear or zigzagging behavior of both the Chamber as of its ministers and member attorneys; an analysis of such behavior; and an exhaustive count of rulings. The result is different from that of the first and second studies: although some vacillations of the Supreme Court persist, now during 2020 there is an increase in topics with uniform jurisprudence. However, some erratic conduct of some of its member ministers and member attorneys is maintained.

\footnotetext{
* Profesor Titular de Derecho Administrativo, Pontificia Universidad Católica de Chile. Post Doctorado en Derecho, Université de Pau et des Pays de l'Adour, Francia. Doctor en Derecho, Universidad de Navarra, España. Correo electrónico: alejandro.vergara@ uc.cl. Dirección postal: Avenida Bernardo O'Higgins 340, Facultad de Derecho, Santiago de Chile.
}

Artículo recibido el 31 de marzo de 2021 y aceptado el 20 de mayo de 2021. 
Palabras clave: Jurisprudencia de derecho administrativo, Vacilaciones de la jurisprudencia, Corte Suprema, ratio iuris decidendi, comportamiento judicial.
Keywords: Jurisprudence of administrative law, vacillations of jurisprudence, Supreme Court, ratio iuris decidendi, judicial behavior.

\section{Introducción}

Esta es la continuación de estudios anteriores; sus versiones anteriores ${ }^{1}$ estuvieron dedicadas a describir la escena jurisprudencial del período 2008-2019 en la Corte Suprema, en veinte temas relevantes de la disciplina del derecho administrativo. La investigación de la jurisprudencia de derecho administrativo podría ser más amplia y cubrir muchos otros temas, los que se suelen incorporar en comentarios de la jurisprudencia, en libros dedicados a la disciplina o en apuntes dirigidos a la enseñanza. Para estas publicaciones, por ahora, he elegido esos veinte temas que son harto actuales y relevantes en la praxis de la disciplina, la que permite ofrecer una muestra de la conducta de jueces y salas de la Corte Suprema. La actual investigación fue realizada sobre un caudal de 329 sentencias de la Corte Suprema del año 2020 en los mismos veinte temas de los dos estudios anteriores.

En esta continuación se mantiene el método de trabajo de los anteriores estudios, como se explica en la primera parte. En la segunda parte se ofrecen los resultados, en tres apartados: el escenario jurisprudencial, explicado; los gráficos y el listado completo de las sentencias respectivas. Cierran el trabajo unas breves conclusiones.

\section{Primera Parte: Método de trabajo y explicación de cada uno de los veinte temas}

1. Método de trabajo: Ratio iuris decidendi idéntica en casos comparados y exhaustividad de la muestra

El método de trabajo que he seguido es el usual en toda recopilación exhaustiva de fuentes del derecho. Es el mismo de las anteriores investiga-

\footnotetext{
1 Este y los anteriores estudios han sido realizados en el marco de las tareas del Observatorio jurisprudencial del Programa de Derecho Administrativo Económico de la Facultad de Derecho de la Pontificia Universidad Católica de Chile. Debo agradecer el valioso trabajo de investigación, fichaje, discusión y gráficos a Carolina Carcamán y Maximiliano Baeza, quienes sucesivamente coordinaron la tarea, y a Francisca Rendich, Ariel Rojas, Nicolás Araya, Pool Tamay y Joaquín Granados, todos investigadores de dicho Programa. La primera versión de este estudio (El derecho administrativo ante la jurisprudencia de la Corte Suprema: Líneas y vacilaciones. Veinte temas, diez años (2008-2018), fue publicada en esta Revista № 28 (2019) Número especial, 184. La segunda versión del estudio (El derecho administrativo ante la jurisprudencia de la Corte Suprema, II: Líneas y vacilaciones durante 2019) fue publicada en esta Revista No 31 (2020), 251-299. Puede verse también sobre las repercusiones del Estudio: Carcamán Rodríguez, Carolina. 2020. Crónica de las repercusiones del Estudio: "El derecho administrativo ante la jurisprudencia de la Corte Suprema: Líneas y vacilaciones", publicado en esta Revista, Nº 28 (2019), 301-305 [todos alojados en el sitio web de la Revista y en los sitios en que se encuentra indexada].
} 
ciones, que puedo sintetizar así: Se inicia con la selección de sentencias de cada uno de los temas de la muestra (i); y, para darle validez a la muestra, se verifica que haya exactitud o igualdad en la ratio iuris decidendi de todos los casos que se comparan (ii).

i) selección de las sentencias. La selección de las sentencias tiene que ser el resultado de una búsqueda rigurosa (en este caso en: www.poderjudicial.cl, sin perjuicio de la ayuda inestimable que proveen otras bases de datos confiables). De esas bases se han seleccionado todas las sentencias. De este modo esta muestra permite ofrecer la conclusión que se busca: la linealidad o vacilación de la jurisprudencia en cada tema analizado.

ii) igualdad o exactitud de la materia y casos de la muestra. Ratio iuris decidendi. Si bien es verdad que cada caso es distinto (ello es obvio: suelen ser distintas las partes, las épocas o el origen del conflicto, etc.), la muestra se realizó luego de un trabajo previo de reducción de la temática de cada sentencia hasta llegar a la identificación de las respuestas jurisprudenciales a una temática muy específica, casi siempre a la interpretación de una misma norma, o conjunto de normas, o a una identidad del factum, esto es, de los hechos. Esto es, a una misma ratio iuris decidendi [=razón jurídica de la decisión]. De ahí que podemos decir que en todas las sentencias colacionadas en cada caso hay identidad de base fáctica y regulatoria: unos mismos hechos y un mismo derecho de base y, por ende, una misma (o desigual) ratio iuris decidendi para una causa igual.

Explico lo anterior pues la pretensión de este estudio es que todos los casos colacionados para cada materia sean una muestra empíricamente comparable, y así ser la base exacta de las conclusiones que se buscan: la linealidad o vacilación de la jurisprudencia.

\section{Explicación de cada tema e información que ahora se ofrece}

En la primera publicación de esta investigación cada uno de los veinte temas fue explicado considerando y ofreciendo la siguiente información: i) los hechos que dan origen al tipo de conflicto y la regulación del mismo; ii) la ratio iuris decidendi específica de cada tema; iii) el escenario jurisprudencial; y iv) gráficos de comportamiento de salas, ministros y abogados integrantes.

Al respecto, en esta publicación, referida a los mismos veinte temas: omitimos completamente la información ofrecida en i) y ii), por lo que cabe remitirse a lo allí explicado; ello para evitar repeticiones en este sitio; pero, se ofrece una información enteramente nueva (como es natural) y relativa a los resultados del año 2020, en cuanto a las informaciones referidas en iii) y iv), esto es: el escenario jurisprudencial y los gráficos.

De ahí que en la Segunda Parte la explicación de cada tema esté referido al escenario jurisprudencial y a los gráficos respectivos. Además, al final se agregan los listados de sentencias. 


\section{Segunda Parte: Veinte temas de derecho administrativo ante la Corte} Suprema (2020)

Cabe advertir que este es un trabajo de recopilación de sentencias sobre los veinte temas que se indican. Al realizar esta búsqueda en algunos casos no se encontró sentencia alguna referida al tema respectivo; ello ocurrió en los temas de los números 11,19 y 20. Si bien tales temas se mantuvieron en la numeración y subtítulos, ahí solo se consigna esta circunstancia.

A. Escenario jurisprudencial en cada tema

I. Conflictos durante el procedimiento administrativo

1. Cómputo de plazos durante la tramitación del procedimiento administrativo Escenario jurisprudencial 2020

a) Conducta de la sala. La jurisprudencia de la Corte Suprema se mantuvo uniforme en esta materia, aplicando adecuadamente la regla del artículo 25 de la LBPA. De esta manera, mantuvo la tendencia sostenida en años anteriores, en que resolvió de la misma forma.

b) Conducta de ministros y abogados integrantes. Todos los ministros y abogados integrantes de la Tercera Sala se inclinaron por la misma postura, en orden a aplicar correctamente lo dispuesto en el artículo 25 de la LBPA. No se presentaron cambios de criterio ni tampoco vacilaciones, manteniendo una tendencia uniforme con lo resuelto durante el año 2019.

\section{Gráficos}

Véase Gráficos 1.1 y 1.2, más adelante.

2. Plazos fatales para que la Administración responda solicitudes del ciudadano. Las demoras o dilaciones de la Administración

\section{Escenario jurisprudencial 2020}

a) Conducta de la sala. La Tercera Sala de la Corte Suprema mantuvo un criterio lineal durante el 2020, optando en todos los casos por la inexistencia de plazos fatales para la Administración. Marca una diferencia con el año 2019, en donde en Clínica Alemana (2019) y Reveco (2019) se manifestaron a favor de la postura del decaimiento.

b) Conducta de ministros y abogados integrantes. Tanto ministros como abogados integrantes uniformaron sus posturas, inclinándose por la inexistencia de plazos fatales, dejando atrás las vacilaciones sostenidas durante el período 2008-2019. El ministro S. Muñoz pasa de una postura pro cumplimiento de plazos por la Administración en Reveco (2019), a sostener de manera uniforme la postura mayoritaria. No existe ninguna disidencia durante el año. 


\section{Gráficos}

Véase Gráficos 2.1 y 2.2, más adelante.

\section{Audiencia previa como requisito esencial del procedimiento administrativo de invalidación}

\section{Escenario jurisprudencial 2020}

a) Conducta de la sala. La Tercera Sala de la Corte Suprema inicia el año manteniendo el mismo comportamiento del período 2008-2019, en cuanto a reconocer la esencialidad de la audiencia previa. Sin embargo, en JB Solutions SpA (2020), en votación dividida, innova de manera extravagante y cambia de parecer, admitiendo como audiencia previa una reunión meramente informativa, cuestión no contemplada en la ley. Posteriormente, vuelve a sostener el criterio inicial, optando por la esencialidad de la audiencia previa del interesado, incurriendo así en un zigzag jurisprudencial.

b) Conducta de ministros y abogados integrantes. En este asunto, los ministros S. Muñoz, Vivanco y el abogado integrante Pallavicini, permanecen uniformes reconociendo la esencialidad de la audiencia previa del interesado. Por su parte, la ministra Sandoval incurre en un zigzag, al aceptar en JB Solutions SpA (2020) la reunión meramente informativa previa para el cumplimiento de lo dispuesto en el artículo 53 de la LBPA, y posteriormente regresar a la postura que reconoce la esencialidad de tal audiencia.

\section{Gráficos}

Véase Gráficos 3.1 y 3.2, más adelante.

\section{4. $\quad$ Plazo de la administración para ejercer potestad sancionatoria}

\section{Escenario jurisprudencial 2020}

a) Conducta de la sala. Durante el año 2020, la Corte Suprema mantiene un criterio uniforme, consistente en aplicar el plazo de cinco años contemplado en el Código Civil, como plazo de la Administración para ejercer la potestad sancionatoria, manteniendo la postura del 2019 y ratificando el cambio de comportamiento en relación al período 2008- 2018, en que zigzagueó en diferentes oportunidades. En tal sentido, no se produjeron zigzagueos durante el 2020, contrario a lo sucedido en años anteriores.

b) Conducta de ministros y abogados integrantes. En el año 2020, los ministros y abogados integrantes tanto de la Primera como de la Tercera Sala aplican el Código Civil. Salvo el abogado integrante Pallavicini, que en Universidad de Chile II (2020), de manera disidente, plantea que se debe aplicar el Código Penal.

\section{Gráficos}

Véase Gráficos 4.1 y 4.2, más adelante. 
5. Agotamiento de la vía administrativa e interrupción del plazo para ejercer posteriores recursos jurisdiccionales

Escenario jurisprudencial 2020

a) Conducta de la sala. Durante el año 2020, la Corte Suprema ha sostenido una conducta uniforme, libre de vacilaciones y cambios de criterio, reconociendo el derecho a interrupción contemplado en el artículo 54 inc. $2^{\circ}$ de la LBPA. Esto es consistente con la postura sostenida durante el 2019, en que se mantuvo invariable en el mismo razonamiento. Así, desde 2006 la CS ha sido consistente, salvo dos casos, uno de 2009 y otro de 2010.

b) Conducta de ministros y abogados integrantes. Tanto ministros como abogados integrantes han mantenido una única línea jurisprudencial, optando por la postura de reconocer la señalada interrupción del artículo 54 inc. $2^{\circ}$ LBPA. No existieron vacilaciones ni cambios de criterio respecto a sus votos del año 2019.

Gráficos

Véase Gráficos 5.1 y 5.2, más adelante.

II. Conflictos al presentar recursos jurisdiccionales

6. Plazo de prescripción de la acción de nulidad administrativa

Escenario jurisprudencial 2020

a) Conducta de la sala. La jurisprudencia de la Tercera Sala, en la única sentencia dictada durante 2020 acerca de esta materia, en Moya (2020), mantuvo la postura de los años anteriores (2008-2019), aplicando las reglas del Código Civil respecto a la prescripción de la acción de nulidad administrativa cuando existe un componente patrimonial.

b) Conducta de ministros y abogados integrantes. Durante el 2020, las ministras Sandoval y Repetto, junto a los abogados integrantes Quintanilla y Pierry aplicaron el Código Civil respecto de los efectos patrimoniales de la acción; mientras que el ministro S. Muñoz mantuvo su voto tradicional en la materia, y optó por la imprescriptibilidad de la acción de nulidad, manteniendo todos ellos sus respectivas posturas sostenidas durante el 2019 y años anteriores.

Gráficos

Véase Gráficos 6.1 y 6.2, más adelante.

7. Cómputo del plazo para presentar recursos jurisdiccionales contra actos administrativos

Escenario jurisprudencial 2020

a) Conducta de la sala. La jurisprudencia de la Tercera Sala se mantuvo invariable durante el año 2020, fallando todos los casos estudiados conforme 
a la norma contenida en el art. 25 de la Ley $N^{0}$ 19.880. En esta materia la Sala ha abandonado la conducta zigzagueante que mantuvo hasta 2017.

b) Conducta de ministros y abogados integrantes. Al igual que en el año 2019, todos los ministros y abogados integrantes de la Tercera Sala se inclinaron por la misma tendencia, esta es, aplicar la norma del art. 25 de la Ley $N^{\circ} 19.880$, y ya no se observa el zigzagueo que varios de ellos mantuvieron en los años anteriores.

Gráficos

Véase Gráficos 7.1 y 7.2, más adelante.

8. Prescripción de la acción indemnizatoria de responsabilidad patrimonial de la Administración

Cabe hacer presente que, en el caso de acción llevadas ante organismos de salud pública, se invocó el artículo 40 de la ley 19.966, el cual dispone expresamente un plazo de cuatro años de prescripción para tales. Por tal razón, dichas sentencias fueron excluidas del presente estudio.

\section{Escenario jurisprudencial 2020}

a) Conducta de la sala. La Tercera Sala de la Corte Suprema ha mantenido el criterio sostenido uniformemente durante el período anterior, consistente en que la acción indemnizatoria por falta de servicio, seguida en contra de los órganos administrativos, prescribe de acuerdo al plazo señalado en el artículo 2332 del Código Civil.

b) Conducta de ministros y abogados integrantes. Ministros y abogados integrantes votaron de manera uniforme durante 2020, siguiendo la tendencia del período 2008-2019.

El ministro S. Muñoz mantiene su postura disidente en este aspecto, planteando que las normas contenidas en el Código Civil relativas a la prescripción no son aplicables en materia de acciones indemnizatorias por responsabilidad patrimonial de la Administración del Estado, fundándose principalmente en que los principios inspiradores del Derecho Público no son compatibles con aquellos que se encuentran en el Derecho Privado.

En el caso de las acciones llevadas al alero de la ley 19.966, el ministro S. Muñoz no opuso disidencia. Pues el plazo de cuatro años contemplado en tal ley, sería una disposición expresa y dispuesta para aplicar a la acción que se pretende ejecutar, lo que no generaría un conflicto con los principios inspiradores del Derecho Público.

\section{Gráficos}

Véase Gráficos 8.1 y 8.2, más adelante. 
9. Prescripción de la acción indemnizatoria por crímenes de lesa humanidad por agentes del Estado

\section{Escenario jurisprudencial 2020}

a) Conducta de la sala. Desde fines del 2014 existe en la Segunda Sala de la Corte Suprema una jurisprudencia asentada tendiente a aceptar la imprescriptibilidad de la acción indemnizatoria por crímenes de lesa humanidad. Tal escenario se mantuvo durante el 2020 con once sentencias en las que la Corte reafirmó el carácter imprescriptible de esta acción patrimonial en tales casos.

b) Conducta de ministros y abogados integrantes. La generalidad de los ministros y abogados integrantes de la segunda sala de la Corte Suprema han mantenido su posición, sin variaciones ni zigzagueos, manteniendo así el comportamiento lineal sostenido desde el 2014, en cuanto a declarar la imprescriptibilidad de la acción indemnizatoria por crímenes de lesa humanidad.

La salvedad la presenta el abogado integrante Lagos, quien ha optado por declarar la prescripción de la acción indemnizatoria cada vez que ha integrado la sala durante el 2020, generando un cambio en relación con el año 2019, en el que las decisiones eran unánimes al declarar la imprescriptibilidad de la acción. Sin embargo, su postura es coincidente con lo que él mismo planteó durante el período 2008-2018.

\section{Gráficos}

Véase Gráficos 9.1 y 9.2, más adelante.

\section{Legitimación activa para ejercer la acción de protección}

\section{Escenario jurisprudencial 2020}

a) Conducta de la sala. A diferencia de lo ocurrido en 2019, durante el año 2020 la Corte Suprema conoció una gran cantidad de casos en esta materia, principalmente relacionadas con el covid-19 y sus consecuencias. En ese contexto, la Tercera Sala mantuvo una absoluta uniformidad en su criterio, exigiendo un grado de determinación más estricto respecto a la individualización del afectado en el recurso de protección. Lo anterior confirma lo sucedido durante el período 2008-2018, en donde, salvo en Confederación Trabajadores (2017), la Corte se pronunció en tal sentido.

b) Conducta de ministros y abogados integrantes. Ministros y abogados integrantes se mantuvieron uniformes en su postura de exigir una mayor precisión a la hora de determinar al afectado. Zigzaguea el ministro S. Muñoz, quien en los casos Muñoz I (2020), Asociación III (2020), Neira (2020), opta por exigir un grado de precisión menos estricto respecto a la individualización del afectado.

\section{Gráficos}

Véase Gráficos 10.1 y 10.2, más adelante. 


\section{Procedencia y alcance de la acción de mera certeza}

\section{Escenario jurisprudencial 2020}

No existieron pronunciamientos acerca de este tema por parte de las salas de la Corte Suprema durante 2020.

III. Conflictos relativos a la estabilidad de los trabajadores en la administración

\section{Funcionarios a honorarios y supletoriedad del Código del Trabajo}

\section{Escenario jurisprudencial 2020}

a) Conducta de la sala. La jurisprudencia de la Cuarta Sala, durante el año 2020 mantuvo los zigzagueos observados en períodos anteriores, al resolver algunos casos aplicando las normas del Código del Trabajo y otros dejando de aplicar tales normas. Es especialmente discutida dentro de la sala la aplicación de la nulidad del despido, contemplada en el art. 162 del Código del Trabajo, respecto de las vinculaciones nacidas al interior de órganos de la Administración pero sobre la base de un contrato a honorarios. Se puede decir que la Cuarta Sala volvió a su conducta zigzagueante, pues el año 2019 había ofrecido una sorprendente uniformidad, desde junio a diciembre (desde Dominguez, 2019, en adelante), marcando una diferencia con sus constantes zigzag anteriores. Este breve tiempo de uniformidad se terminó en febrero de 2020, con Ayacán (2020), y en tres ocasiones posteriores: Poblete (2020), Aldana (2020) y Vargas (2020), cuyas causas son idénticas en sus bases jurídicas, por lo que es inexplicable el cambio.

b) Conducta de ministros y abogados integrantes. Continúan los zigzagueos de los años anteriores de los ministros Blanco, M. Silva y A. Muñoz, y ahora también de la nueva ministra Repetto, oscilando entre la tendencia que decide no aplicar las normas del Código del Trabajo y aquella que sí, previa distinción de la naturaleza del vínculo entre la persona y la Administración, nacida en virtud de un contrato a honorarios. Estos cambios son los que explican y provocan el zigzagueo de la Sala. Por su parte, la ministra Chevesich se mantiene absolutamente estable en su votación, como en todos los períodos anteriores revisados en este Estudio.

Gráficos

Véase Gráficos 12.1 y 12.2, más adelante.

\section{Término anticipado de empleos a contrata}

Escenario jurisprudencial 2020

a) Conducta de la Tercera Sala. Después de analizada la jurisprudencia dictada por la Tercera Sala durante el 2020, se concluye que si bien en la mayoría de los casos se acogen los recursos respectivos, no aceptando la 
precariedad del empleo a contrata; no obstante, existen seis casos en los que continúan los zigzagueos. En efecto, en la mayoría de las sentencias la sala opta por declarar la vulneración a los derechos de los empleados a contrata con la terminación de tales empleos, principalmente en virtud de la garantía constitucional de la igualdad ante la ley. Usualmente la integración de la sala es similar, y este zigzagueo se explica únicamente en el cambio de los votos de tres de sus ministros, como se revisa a continuación.

b) Conducta de ministros y abogados integrantes. Durante el año 2020, se mantienen estables y con una votación absolutamente lineal, aunque en sentido contrario, tanto el ministro S. Muñoz, quien no acepta la precariedad de los empleos a contrata y el abogado integrante Pallavicini, quien sí acepta dicha precariedad al estimar que la autoridad se encuentra legalmente facultada para poner término al vínculo emanado de la contrata, sin importar el tiempo que la persona lleve vinculada a la Administración. Ambos han mantenido esta conducta lineal durante muchos años, como se observa en las entregas anteriores de este Estudio.

No obstante, continúan con su conducta anterior altamente zigzagueante las ministras Vivanco y Sandoval y el abogado integrante Pierry (como se puede ver en los resultados anteriores de este Estudio), cuyos cambios de voto en causas idénticas es lo que origina que la sala continúe ofreciendo sentencias zigzagueantes. Además, se produce una dispersión de sus votos, lo que hace impredecible los resultados de la Sala, por la inconsistencia de tales ministras y abogado integrante de lo que pareciera ser su posición doctrinaria (si es que podemos afirmar que la haya). En efecto, por una parte, Pierry y Sandoval en la mayoría de los casos aceptan la precariedad del empleo a contrata, pero en algunos casos votan por la posición contraria en casos idénticos; y, por otra parte, Vivanco, al contrario, si bien suele no aceptar la precariedad en una mayoría de casos, pero en casos idénticos vota en sentido contrario. En las sentencias respectivas no se ofrece ninguna explicación a estos constantes cambios de votos.

Véase, respecto del abogado integrante Pierry, los casos: Santos (2020) y Vargas (2020).

Respecto de la ministra Sandoval, los casos: Gutiérrez (2020), Villalobos (2020), Miranda (2020), Salgado (2020), Navarrete (2020), Franjola (2020), Zumelzu (2020), Suazo (2020), García (2020), Araya (2020) y Castañeda (2020).

Respecto de la ministra Vivanco, los casos: Ormeño (2020), Soto (2020), Williams (2020), Smirnov (2020), Caruncho (2020) e Inostroza (2020).

Gráficos

Véase Gráficos 13.1 y 13.2, más adelante. 


\section{Desviación de poder en las desvinculaciones de los funcionarios a contrata}

\section{Escenario jurisprudencial 2020}

a) Conducta de la sala. Durante el año 2020 se verifica una uniformidad en reconocer la desviación de poder como vicio de ilegalidad en los casos de desvinculaciones de funcionarios a contrata.

Esto representa un escenario fuertemente contrastante con el existente durante los años 2014 a 2019, caracterizados por los constantes zigzagueos en que incurrió la Sala.

b) Conducta de ministros y abogados integrantes. En la medida en que la conducta de los ministros y abogados integrantes de la Sala es uniforme se produce, como consecuencia, la uniformidad señalada en los resultados de la jurisprudencia de la Sala, en reconocer la desviación de poder como vicio de ilegalidad. En este sentido, destacan los votos constantes y reiterados de los ministros S. Muñoz, Sandoval, Vivanco y Llanos a favor de reconocer la desviación de poder.

En contraste, el abogado integrante Pallavicini, quien tradicionalmente había sido uniforme en no aceptar la desviación de poder como vicio de legalidad en estas desvinculaciones (en consistencia con sus votos en el tema 13, relativo a la precariedad del empleo a contrata), incurre en un zigzag en Gálvez (2020), en que se manifiesta a favor de la postura mayoritaria; posteriormente vuelve a su criterio tradicional en las dos ocasiones siguientes en que integra: Castillo (2020) y Gómez (2020).

\section{Gráficos}

Véase Gráficos 14.1 y 14.2, más adelante.

\section{Recurso de protección como vía idónea en casos de desvinculación de funcionarios a contrata}

\section{Escenario jurisprudencial 2020}

a) Conducta de la sala. La jurisprudencia se presenta altamente vacilante, existiendo múltiples fallos que rechazan la idoneidad del recurso por razones de fondo, intercalados con otros que acogen los recursos, aceptando su carácter como vía idónea. Dentro de estos, a su vez, existen casos en que se ha fundamentado acoger el recurso por medio de la garantía de la igualdad ante la ley, y otros, menos numerosos, en la garantía de la propiedad; e incluso, de manera sorprendente, en un número considerable de casos la Sala menciona ambas garantías como su fundamento. Muchos otros se refieren de manera general a las "garantías alegadas por la parte recurrente" como fundamentación.

Es posible afirmar, entonces, que la Sala no ha desarrollado una doctrina consistente al respecto. 
Este escenario jurisprudencial es bastante similar al que se ha verificado en los años anteriores, hasta 2019, existiendo ciertos periodos que pudieran calificarse en principio de estabilidad lo que cambia de improviso forjando un panorama caracterizado por un constante zigzagueo.

b) Conducta de ministros y abogados integrantes. Se observa que los ministros de la Tercera Sala zigzaguearon constantemente durante el año 2020, admitiendo y rechazando recursos en casos de desvinculación de funcionarios a contrata. Es, por ejemplo, la conducta (en esto, invariable) de las ministras Sandoval y Vivanco, quienes zigzaguean en numerosas ocasiones. Conductas relativamente uniformes ofrecen, por una parte, el ministro S. Muñoz, quien se pronuncia regularmente por aceptar el recurso de protección como vía idónea, salvo en cuatro casos en que zigzaguea: Herrera (2020), Díaz III (2020), Quezada I (2020) y Pérez (2020); y, por otra parte, el abogado integrante Pallavicini, quien, por el contrario, se pronuncia regular y reiteradamente por rechazar los recursos por razones de fondo, salvo en un caso, en que zigzaguea: González II (2020).

Gráficos

Véase Gráficos 15.1 y 15.2, más adelante.

IV. Conflictos en recursos naturales, medio ambiente y bienes públicos

16. Regularización de derechos de aguas

Escenario jurisprudencial 2020

a) Conducta de la sala. Durante el año 2020, la Tercera Sala de la Corte Suprema tuvo una conducta zigzagueante, que ha sido constante desde el año 2016, en contraste con épocas anteriores en que mantenía una mayor uniformidad de criterio.

En particular, en el inicio del 2020, la sala se manifestó repetidamente a favor de la regularización de derechos de aprovechamiento de aguas, fundándose en que la transitoriedad del artículo $2^{\circ}$ transitorio del Código de Aguas no implica desconocer el derecho de quienes están actualmente utilizando las aguas y han sido precedidos en el uso por causahabientes desde un tiempo anterior al exigido por la señalada norma. Así, admitió el derecho a sumar la posesión del derecho de aguas de los predecesores en el dominio del inmueble.

Sin embargo, en abril, en Meta (2020) desconocen lo resuelto anteriormente, para pronunciarse en contra de la regularización, entendiendo que el uso exigido por el artículo $2^{\circ}$ transitorio debe ser personalísimo. Luego, a partir de Mulet (2020), la Tercera Sala opta nuevamente por acceder a la regularización, manteniendo. Todas las causas anteriores son idénticas. 
b) Conducta de ministros y abogados integrantes. Manifiestan uniformemente una postura a favor de la regularización de derechos de aguas, durante el año 2020, los ministros J. Muñoz, Vivanco y S. Muñoz.

En tanto, los ministros Sandoval, Prado y el abogado integrante Quintanilla, se mantienen invariables en su parecer de rechazar la regularización, bajo el argumento de que el artículo $2^{\circ}$ transitorio del Código de Aguas está contemplado para el uso que realice personalmente el solicitante de la regularización.

Por su parte, cambió de parecer durante el 2020 el ministro Llanos, cuestión que resultó determinante para el único zigzag del año en Meta (2020), en donde rechazó la regularización invocando la necesidad de un uso personalísimo de las aguas, para posteriormente en Comercial (2020), manifestarse a favor de la regularización, desconociendo lo resuelto pocos meses atrás.

\section{Gráficos}

Véase Gráficos 16.1 y 16.2, más adelante.

\section{Autorizaciones administrativas como requisito de servidumbres mineras}

\section{Escenario jurisprudencial 2020}

a) Conducta de la sala. Durante el año 2020, la Corte Suprema solo se pronunció en una oportunidad acerca de las autorizaciones administrativas como requisito de servidumbres mineras. Esto ocurrió en Muñoz (2020), en que la Cuarta Sala señaló que no puede rechazarse la constitución de la servidumbre minera invocando la normativa administrativa del Plan Regulador Intercomunal del Borde Costero de la Región de Antofagasta. Con ello, mantiene la tendencia que viene sosteniendo desde Sociedad Legal Minera Juan Pablo II Primera de Antofagasta (2017), ya que desde entonces la Cuarta Sala ha fallado de manera uniforme, al exigir exclusivamente el cumplimiento de los requisitos contenidos en la legislación minera para la constitución de las servidumbres mineras. Ya no se observa el zigzag en que incurrió desde 2014 hasta octubre de 2017, en el caso Sociedad Legal Minera Juan Pablo II Tercera de Antofagasta (2017).

b) Conducta de ministros y abogados integrantes. Las ministras Chevesich y A. Muñoz mantienen de manera uniforme sus votos sostenidos en casos anteriores, desde 2014, optando por exigir solo requisitos de la legislación minera. A esta misma postura se ha unido la ministra Repetto en Muñoz (2020).

El ministro Blanco, por su parte, permanece de manera uniforme en su postura (esta vez disidente) de exigir para la constitución de las servidumbres mineras el cumplimiento de la normativa especial contenida en diversos instrumentos de planificación territorial.

Gráficos

Véase Gráficos 17.1 y 17.2, más adelante. 


\section{Plazo para que tercero absoluto pueda solicitar invalidación ambiental}

Escenario jurisprudencial 2020

a) Conducta de la sala. Durante el año 2020, la Corte Suprema solo se pronunció en una oportunidad acerca del plazo para que un tercero absoluto pueda solicitar la invalidación ambiental. Tal situación ocurrió en Stipicic (2020), en donde, en votación dividida, declaró que el plazo para solicitar la invalidación ambiental es de treinta días, sin importar la calidad que el reclamante haya poseído en el procedimiento de calificación ambiental. Ello marca un cambio de criterio respecto a la postura sostenida en Comunidad (2019), manteniendo así el continuo zigzagueo sostenido durante el período anterior, desde 2015 a 2018.

b) Conducta de ministros y abogados integrantes. Comparando la postura de los ministros con sus votos de años anteriores, podemos concluir que el ministro S. Muñoz se mantiene uniforme con su parecer de aplicar el plazo de dos años en dos casos de 2017: Maturana y Corporación.

Por su parte, la ministra Sandoval vuelve a optar ahora en Stipicic (2020), como lo había hecho en casos de 2016, 2017 y 2018, por la aplicación del plazo de treinta días para que un tercero absoluto pueda solicitar la invalidación ambiental. Ello sin perjuicio de que en Comunidad (2019) de manera implícita optó por el plazo de dos años.

\section{Gráficos}

Véase Gráficos 18.1 y 18.2, más adelante.

\section{Afectación presunta de bienes privados al uso público}

\section{Escenario jurisprudencial 2020}

La Corte Suprema no conoció casos de afectación presunta de bienes privados al uso público durante el año 2020.

\section{Acceso a playas públicas}

Escenario jurisprudencial 2020

La Corte Suprema no conoció casos relativos al acceso a playas públicas durante el año 2020. 


\section{B. Gráficos}

Gráfico 1.1. Comportamiento de la sala: Cómputo de plazos durante la tramitación del procedimiento administrativo

\begin{tabular}{|c|c|c|}
\hline AÑ̃o & $\begin{array}{l}\text { CASOS QUE APLICAN CORRECTAMENTE ART. } 25 \\
\text { LBPA }\end{array}$ & $\begin{array}{c}\text { CASOS QUE NO APLICAN CORRECTAMENTE } \\
\text { REGLA ART. 25 LBPA }\end{array}$ \\
\hline \multirow[t]{6}{*}{2020} & TELEVISIÓN NACIONAL DE CHILE & \\
\hline & CALTEC SPA & \\
\hline & ANTOFAGASTA MINERALS & \\
\hline & SECURITY EVENT SPA & \\
\hline & ORTEGA & \\
\hline & ENEL & \\
\hline
\end{tabular}

Gráfico 1.2. Comportamiento de ministros y abogados integrantes: Cómputo de plazos durante la tramitación del procedimiento administrativo

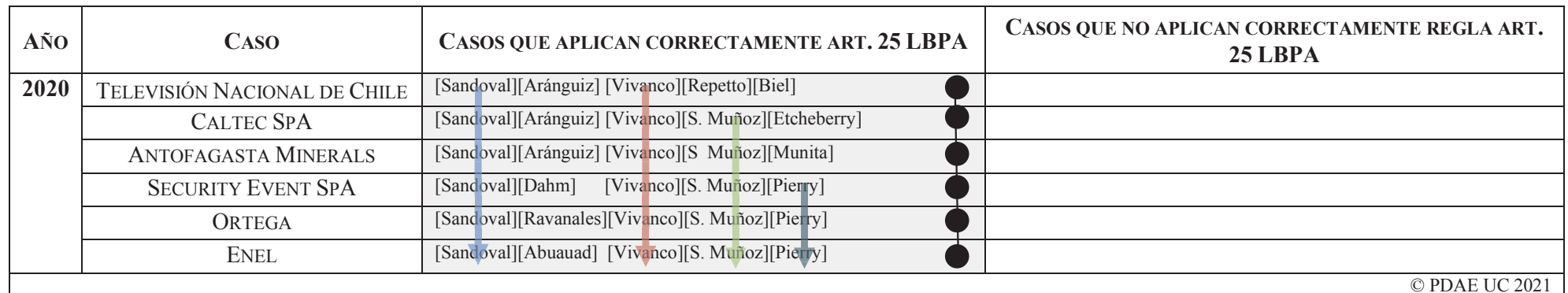

Gráfico 2.1. Comportamiento de la sala: Plazos fatales para que la Administración responda solicitudes del ciudadano. Las demoras o dilaciones de la Administración

\begin{tabular}{|l|l|c|c|}
\hline \multirow{3}{*}{ AÑ } & \multicolumn{2}{|c|}{ ARTÍCULO 27 LBPA NO ES FATAL } & POSTURA PRO CUMPLIMIENTO DE \\
& \multicolumn{1}{|c|}{$\begin{array}{c}\text { SOSTIENEN INEXISTENCIA DE } \\
\text { PLAZOS FATALES }\end{array}$} & POSTURA DEL DECAIMIENTO & PLAZOS POR LA ADMINISTRACIÓN \\
\hline \multirow{3}{*}{2020} & KDM S.A. & & \\
\cline { 2 - 4 } & INDUSTRIAL TEXTIL & & \\
\cline { 2 - 4 } & VELÁSQUEZ & & \\
\cline { 2 - 4 } & CARRILLO & & C PDAE UC 2021 \\
\cline { 2 - 4 } & REYES & & \\
\hline
\end{tabular}

Gráfico 2.2. Conducta de los ministros: Plazos fatales para que la Administración responda solicitudes del ciudadano. Las demoras o dilaciones de la Administración

\begin{tabular}{|c|c|c|c|c|}
\hline \multirow[b]{2}{*}{ AÑo } & \multirow[b]{2}{*}{ CASO } & \multicolumn{2}{|c|}{ ARTÍCULO 27 LBPA NO ES FATAL } & \multirow[b]{2}{*}{$\begin{array}{l}\text { POSTURA PRO CUMPLIMIENTO DE PLAZOS } \\
\text { POR LA ADMINISTRACIÓN }\end{array}$} \\
\hline & & $\begin{array}{l}\text { SOSTIENEN INEXISTENCIA DE PLAZOS } \\
\text { FATALES }\end{array}$ & POSTURA DEL DECAIMIENTO & \\
\hline \multirow{5}{*}{2020} & KDM S.A. & [S. Muñoz][A. Muñoz][Vivanco][Repetto][Biel] & 9 & \\
\hline & INDUSTRIAL TEXTIL & [S. Muñoz][Prado][Llanos] & 0 & \\
\hline & VELÁSQUEZ & [S. Muñoz][Sandoval][Vivanco][Quintanilla][Lagos] & 0 & \\
\hline & CARRILLO & [S. Muñoz][Sandoval][Vivanco][Pallavicini][Pierry] & 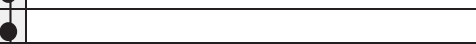 & \\
\hline & REYES & [Munita] [Sandoval][Vivañco][Pallavicini][Prado] & 0 & \\
\hline
\end{tabular}

Gráfico 3.1. Comportamiento de la sala: Audiencia previa como requisito esencial del procedimiento administrativo de invalidación

\begin{tabular}{|c|c|c|c|}
\hline AÑ̃ & $\begin{array}{c}\text { RECONOCE ESENCIALIDAD DE PREVIA AUDIENCIA } \\
\text { DEL INTERESADO }\end{array}$ & $\begin{array}{c}\text { ACEPTA REUNIÓN MERAMENTE INFORMATIVA } \\
\text { PREVIA }\end{array}$ & $\begin{array}{c}\text { NO RECONOCE ESENCIALIDAD DE PREVIA } \\
\text { AUDIENCIA DEL INTERESADO }\end{array}$ \\
\hline \multirow[t]{7}{*}{2020} & DEL PINO & & \\
\hline & COEXCA S.A. & & \\
\hline & SEPÚLVEDA & & \\
\hline & LUNA & & \\
\hline & [voto] & JB SOLUTIONS & \\
\hline & COMUNIDAD INDÍGENA & & \\
\hline & SERVICIO DE EVALUACIÓN AMBIENTAL & & \\
\hline
\end{tabular}

Gráfico 3.2. Comportamiento de los ministros: Audiencia previa como requisito esencial del procedimiento administrativo de invalidación

\begin{tabular}{|c|c|c|c|c|}
\hline AÑo & CASO & $\begin{array}{l}\text { RECONOCE ESENCIALIDAD DE PREVIA } \\
\text { AUDIENCIA DEL INTERESADO }\end{array}$ & $\begin{array}{l}\text { ACEPTA REUNIÓN MERAMENTE INFORMATIVA } \\
\text { PREVIA }\end{array}$ & $\begin{array}{c}\text { NO RECONOCE ESENCIALIDAD DE PREVIA } \\
\text { AUDIENCIA DEL INTERESADO }\end{array}$ \\
\hline \multirow[t]{7}{*}{2020} & DEL PINO & [Sandoval][Vivanco][S. Muñoz][Aránguiz][Etcheberry] & & \\
\hline & CoEXCA S.A. & [Sandoval][Vivanco][Llanos][Lagos] [Pallavicini] & & \\
\hline & SEPÚLVEDA & [Sandoval][Vivanco][S. Muñoz][Zepeda][Pallawigini] & & \\
\hline & LUNA & [Sandoval][Vivanco][J. Muñoz][Lagos][Pierry] & & \\
\hline & JB SOLUTIONS & [Vivanco][S. Muñoz] & [Sandoval][Quintanilla][Munita] & \\
\hline & $\begin{array}{l}\text { COMUNIDAD } \\
\text { INDÍGENA }\end{array}$ & [Llanos] [Vivanco][S .Muñoz][Mera][Etcheberry] & & \\
\hline & $\begin{array}{c}\text { SERVICIO DE } \\
\text { EVALUACIÓN } \\
\text { AMBIENTAL }\end{array}$ & [Sardoval][Vivanco][S. Muñoz][Quintanilla][Pierry] & & \\
\hline
\end{tabular}


Gráfico 4.1. Comportamiento de la sala: Plazo de la Administración para ejercer potestad sancionatoria

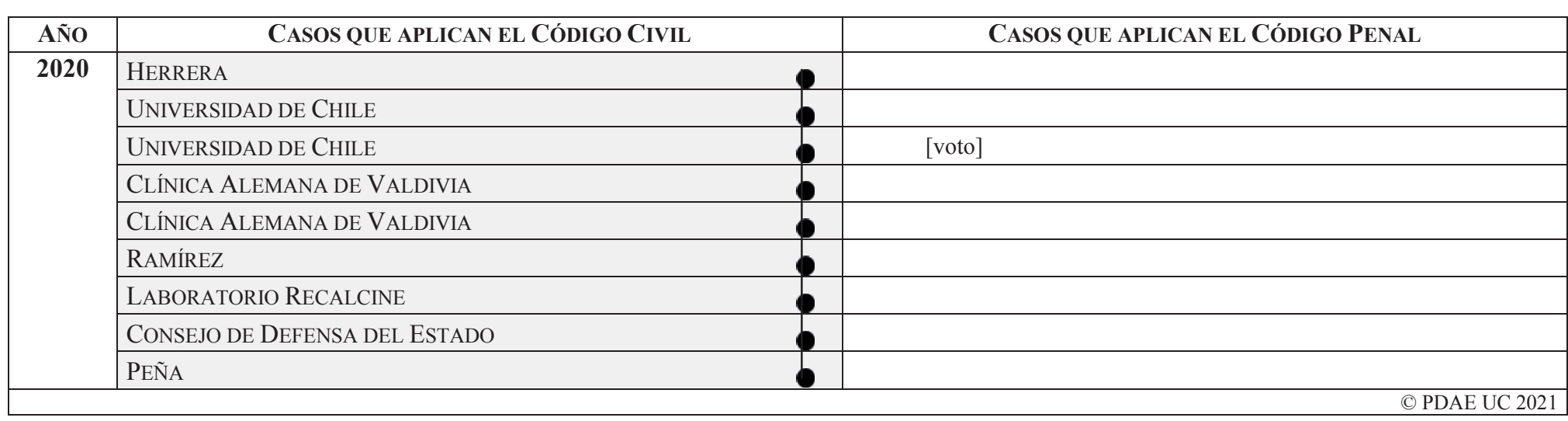

Gráfico 4.2. Comportamiento de ministros y abogados integrantes: Plazo de la Administración para ejercer potestad sancionatoria

\begin{tabular}{|c|c|c|c|}
\hline AÑ̃o & CASO & CASOS QUE APLICAN EL CÓDIGO CIVIL & CASOS QUE APLICAN EL CÓDIGO PENAL \\
\hline \multirow[t]{6}{*}{2020} & HERRERA & [S. Muñoz] [Sandoval] [Vivanco] [Quintanilla] [Etcheberry] & \\
\hline & UNIVERSIDAD DE CHILE & [S. Muñoz] [Sandoval] [Gómez] [Zepeda] & [Pallavicini] \\
\hline & CLÍNICA ALEMANA DE VALDIVIA & [S. Muñoz] [Sandoval] [Vivanco] [Quintanilla] [Perry] & \\
\hline & RAMÍREZ & [S. Muñoz] [Sandoval] [Vivanco] [Quintanilla] [Lagos] & \\
\hline & LABORATORIO RECALCINE & [Dahm] [Sandoval] [Vivanco] [Quintanilla] [Pierry] & \\
\hline & CONSEJO DE DEFENSA DEL ESTADO & [Künsemüller] [Maggi] [Aránguiz] [Munita] [Gómez] & \\
\hline
\end{tabular}

Gráfico 5.1. Comportamiento de la sala: Agotamiento de la vía administrativa e interrupción del plazo para ejercer posteriores recursos jurisdiccionales

\begin{tabular}{|c|l|c|c|}
\hline \multirow{2}{*}{ AÑo } & \multicolumn{1}{|c|}{$\begin{array}{c}\text { RECONOCE EL DERECHO A INTERRUPCIÓN DEL ART. 54 INC. } 2^{\circ} \\
\text { LBPA }\end{array}$} & $\begin{array}{c}\text { NO RECONOCE EL DERECHO A INTERRUPCIÓN DEL ART. 54 INC. } \mathbf{2}^{\circ} \\
\text { LBPA }\end{array}$ \\
\hline \multirow{2}{*}{$\mathbf{2 0 2 0}$} & OYARZÚN & & \\
\cline { 2 - 4 } & JORQUERA & & \\
\cline { 2 - 5 } & DOTE & & \\
\hline
\end{tabular}

Gráfico 5.2. Comportamiento de ministros y abogados integrantes: Agotamiento de la vía administrativa e interrupción del plazo para ejercer posteriores recursos jurisdiccionales

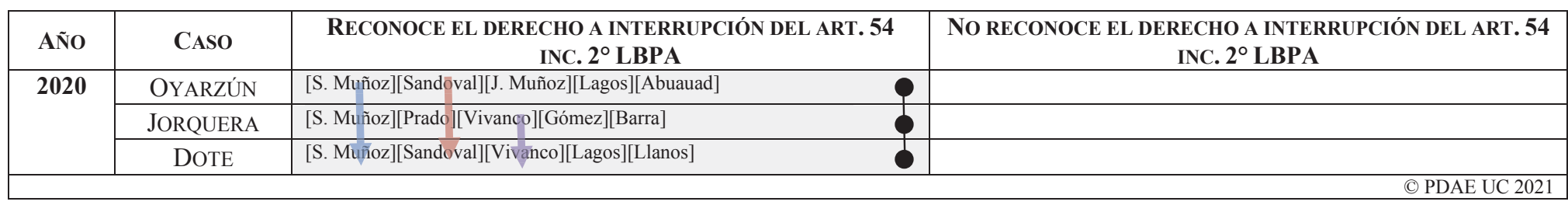

Gráfico 6.1. Comportamiento de la sala: Plazo de prescripción de la acción de nulidad administrativa

\begin{tabular}{|c|c|c|c|}
\hline \multirow{2}{*}{ AÑo } & $\begin{array}{c}\text { LA ACCIÓN DE NULIDAD ESTÁ SUJETA } \\
\text { A LAS REGLAS DE PRESCRIPCIÓN DEL } \\
\text { CC CUANDO TIENE UN COMPONENTE } \\
\text { PATRIMONIAL }\end{array}$ & $\begin{array}{c}\text { LA ACCIÓN DE NULIDAD Y LA ACCIÓN } \\
\text { PATRIMONIAL PRESCRIBEN SEGÚN } \\
\text { LAS REGLAS DEL CC }\end{array}$ & $\begin{array}{c}\text { TANTO LA ACCIÓN DE NULIDAD } \\
\text { COMO SUS EFECTOS PATRIMONIALES } \\
\text { SON IMPRESCRIPTIBLES }\end{array}$ \\
\hline $\mathbf{2 0 2 0}$ & MOYA & & \\
\hline
\end{tabular}

Gráfico 6.2. Comportamiento de ministros y abogados integrantes: Plazo de prescripción de la acción de nulidad administrativa

\begin{tabular}{|c|c|c|c|r|}
\hline AÑo & CASO & $\begin{array}{c}\text { LA ACCIÓN DE NULIDAD ESTÁ SUJETA A LAS } \\
\text { REGLAS DE PRESCRIPCIÓN DEL CC CUANDO } \\
\text { TIENE UN COMPONENTE PATRIMONIAL }\end{array}$ & $\begin{array}{c}\text { LA ACCIÓN DE NULIDAD Y LA ACCIÓN } \\
\text { PATRIMONIAL PRESCRIBEN SEGÚN LAS } \\
\text { REGLAS DEL CC }\end{array}$ & $\begin{array}{c}\text { TANTO LA ACCIÓN DE NULIDAD COMO SUS } \\
\text { EFECTOS PATRIMONIALES SON } \\
\text { IMPRESCRIPTIBLES }\end{array}$ \\
\hline $\mathbf{2 0 2 0}$ & MOYA & [Sandoval] [Repetto] [Quintanilla] [Pierry] & & OS. Muñoz] \\
\hline
\end{tabular}

Gráfico 7.1 Comportamiento de la sala: Cómputo del plazo para presentar recursos jurisdiccionales contra actos administrativos

\begin{tabular}{|c|c|c|c|}
\hline AÑo & APLICAN ART. 25 LBPA & APLICAN ART. 66 CPC & APLICAN ART. 50 CC \\
\hline \multirow[t]{6}{*}{2020} & TVN & & \\
\hline & STAND OFF & & \\
\hline & CALTEC & & \\
\hline & ANTOFAGASTA MINERALS & & \\
\hline & \begin{tabular}{|l|} 
ORTEGA \\
\end{tabular} & & \\
\hline & ENEL & & \\
\hline
\end{tabular}


Gráfico 7.2. Comportamiento de ministros y abogados integrantes: Cómputo del plazo para presentar recursos jurisdiccionales contra actos administrativos

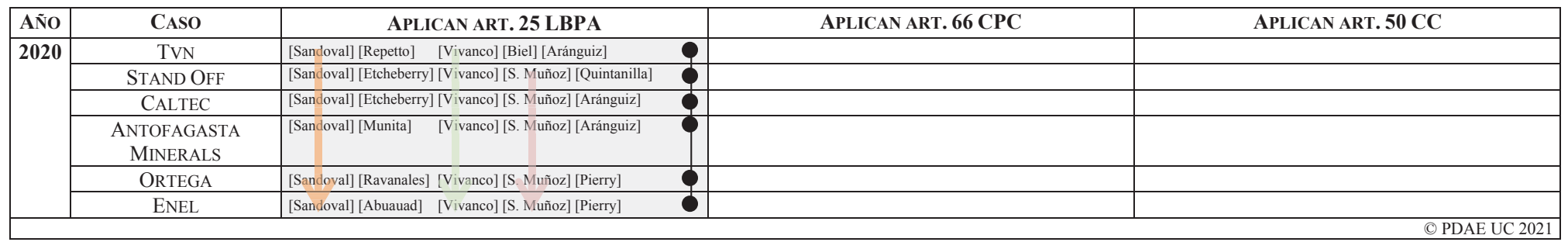

Gráfico 8.1. Comportamiento de la sala: Prescripción de la acción indemnizatoria de responsabilidad

\begin{tabular}{|c|c|c|}
\hline AÑo & $\begin{array}{l}\text { LAS NORMAS DEL CÓDIGO CIVIL SOBRE } \\
\text { PRESCRIPCIÓN NO SON APLICABLES A LA } \\
\text { ACCIÓN INDEMNIZATORIA DE } \\
\text { RESPONSABILIDAD }\end{array}$ & $\begin{array}{l}\text { LAS NORMAS DEL CÓDIGO CIVIL SOBRE } \\
\text { PRESCRIPCIÓN SON APLICABLES A LA } \\
\text { ACCIÓN INDEMNIZATORIA DE } \\
\text { RESPONSABILIDAD }\end{array}$ \\
\hline \multirow[t]{9}{*}{2020} & [voto] & SILVA \\
\hline & [voto] & COLLIHUIN \\
\hline & [voto] & ALARCÓN \\
\hline & [voto] & VERGARA \\
\hline & & MEZA \\
\hline & [voto] & ARAYA \\
\hline & [voto] & ARNABOLDI \\
\hline & [voto] & PHARMAMEDICA \\
\hline & [voto] & GESTIÓN ECOLÓGICA \\
\hline & & (C) PDAE UC 2021 \\
\hline
\end{tabular}

Gráfico 8.2. Comportamiento ministros y abogados integrantes: Prescripción de la acción indemnizatoria de responsabilidad

\begin{tabular}{|c|c|c|c|}
\hline AÑ̃ & CASO & $\begin{array}{l}\text { LAS NORMAS DEL CÓDIGO CIVIL SOBRE } \\
\text { PRESCRIPCIÓN NO SON APLICABLES A LA ACCIÓN } \\
\text { INDEMNIZATORIA DE RESPONSABILIDAD }\end{array}$ & $\begin{array}{l}\text { LAS NORMAS DEL CÓDIGO CIVIL SOBRE } \\
\text { PRESCRIPCIÓN SON APLICABLES A LA ACCIÓN } \\
\text { INDEMNIZATORIA DE RESPONSABILIDAD }\end{array}$ \\
\hline \multirow[t]{6}{*}{2020} & SILVA & [S.Muñoz] & [Sandoval][Silva][Quintanilla][Pallavicini] \\
\hline & ALARCÓN & [S.Muñoz] & [Sandoval][Vivanco][Aránguiz][Pallavicini] \\
\hline & VERGARA & [S.Muñoz] & [Sandoval][Vivanco][Llanos][Zepeda] \\
\hline & MEZA & & [Zepeda][Sandoval][Vivanco][Lagos][Pallavicini] \\
\hline & PHARMAMEDICA & [S.Muñoz] & [Sandoval][Vivanco][Llanos][Quintanilla] \\
\hline & $\begin{array}{c}\text { GESTIÓN } \\
\text { ECOLÓGICA }\end{array}$ & [S.Muñoz] & {$[$ Sandoval][Pierry] [Llanos][Quintanilla] } \\
\hline
\end{tabular}

Gráfico 9.1. Comportamiento de sala: Prescripción de la acción indemnizatoria de crímenes de lesa humanidad por agentes del Estado. [En cada caso se indica la sala que conoció el recurso]

\begin{tabular}{|c|c|c|}
\hline AÑ̃ & $\begin{array}{c}\text { ACCIÓN PRESCRIPTIBLE SEGÚN NORMAS DEL } \\
\text { CÓDIGO CIVIL (ART. 2.332) }\end{array}$ & $\begin{array}{l}\text { ACCIÓN IMPRESCRIPTIBLE POR APLICACIÓN DE } \\
\text { TRATADOS Y CONVENIOS INTERNACIONALES }\end{array}$ \\
\hline \multirow[t]{11}{*}{2020} & & JARPA $\left(2^{a} \mathrm{~S}.\right)$ \\
\hline & [voto] & MARDONES $\left(2^{\mathrm{a}} \mathrm{S}.\right)$ \\
\hline & & SAN MARTÍN (2a S.) \\
\hline & & PROGRAMA LEY $19.123 \mathrm{I}\left(2^{\mathrm{a}} \mathrm{S}.\right)$ \\
\hline & & LEIVA $\left(2^{a} \mathrm{~S}.\right)$ \\
\hline & [voto] & CEVAllos (2a S.) \\
\hline & & CONCHA $\left(2^{\mathrm{a}} \mathrm{S}.\right)$ \\
\hline & & PROGRAMA LEY $19.123 \mathrm{II}\left(2^{\mathrm{a}} \mathrm{S}.\right)$ \\
\hline & & PROGRAMA LEY 19.123 III (2a S.) \\
\hline & & PROGRAMA LEY 19.123 IV (2a S.) \\
\hline & & GUELET $\left(2^{\mathrm{a}} \mathrm{S}\right.$. $)$ \\
\hline & & (C) PDAE UC 2021 \\
\hline
\end{tabular}

Gráfico 9.2. Conducta de los ministros y abogados integrantes: Prescripción de la acción indemnizatoria contra crímenes de lesa humanidad por agentes del Estado

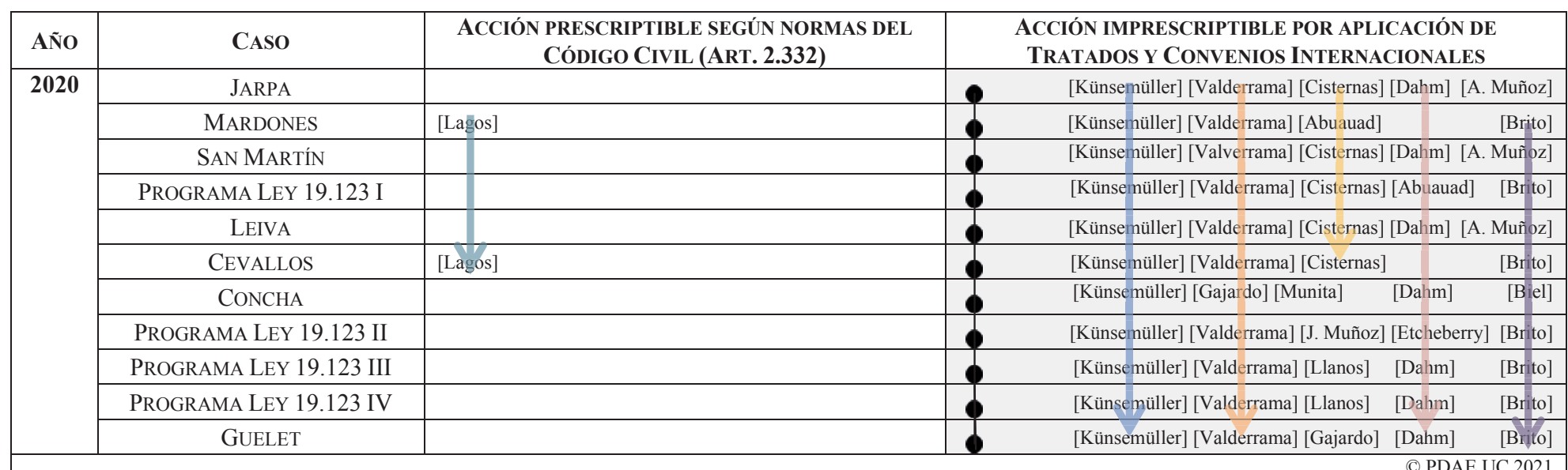


Gráfico 10.1. Comportamiento de la sala: Legitimación activa para ejercer la acción de protección

\begin{tabular}{|c|c|c|}
\hline \multirow[b]{2}{*}{ AÑo } & \multicolumn{2}{|c|}{ EL RECURSO DE PROTECCIÓN NO CONSTITUYE UNA ACCIÓN POPULAR } \\
\hline & $\begin{array}{l}\text { EXIGE UN GRADO DE DETERMINACIÓN MÁS ESTRICTO } \\
\text { RESPECTO A LA INDIVIDUALIZACIÓN DEL AFECTADO }\end{array}$ & \begin{tabular}{|c|} 
EXIGE UN GRADO DE DETERMINACIÓN MENOS \\
ESTRICTO RESPECTO A LA INDIVIDUALIZACIÓN DEL \\
AFECTADO
\end{tabular} \\
\hline \multirow[t]{61}{*}{2020} & REY & \\
\hline & PARTIDO RADICAL & \\
\hline & MuÑOZ I & [voto] \\
\hline & VIDAL & \\
\hline & VALENZUELA & \\
\hline & PÉREZ & \\
\hline & SCAFF I & \\
\hline & SCAFF II & \\
\hline & LOBOS & \\
\hline & MUNICIPALIDAD DE CALDERA & \\
\hline & ASOCIACIÓN I & \\
\hline & FEDERACIÓN & \\
\hline & ALMONACID & \\
\hline & GONZÁLEZ & \\
\hline & SCAFF III & \\
\hline & BARUDY & \\
\hline & CONFEDERACIÓN I & \\
\hline & MUNICIPALIDAD PADRE LAS CASAS & \\
\hline & UNIVERSIDAD & \\
\hline & CRISTI I & \\
\hline & CONFEDERACIÓN DEMOCRÁTICA I & \\
\hline & PEZO & \\
\hline & CABALLERO & \\
\hline & MUNICIPALIDAD DE CERRO NAVIA & \\
\hline & MUÑOZ II & \\
\hline & REBOLLEDO & \\
\hline & MUNICIPALIDAD DE LUMACO & \\
\hline & SINDICATO & \\
\hline & CRISTI II & \\
\hline & ORTEGA & \\
\hline & ASOCIACIÓN DE FUNCIONARIOS & \\
\hline & CORPORACIÓN & \\
\hline & FEDERACIÓN METROPOLITANA & \\
\hline & CERDA & \\
\hline & CONFEDERACIÓN DEMOCRÁTICA II & \\
\hline & ASOCIACIÓN II & \\
\hline & HIRSCH & \\
\hline & SINDICATO & \\
\hline & MUÑOZ III & \\
\hline & INDH & \\
\hline & BARRÍA & \\
\hline & GARCÍA DE LA PASTORA & \\
\hline & ACEVEDO I & \\
\hline & JUNTA DE VECINOS & \\
\hline & PEÑA & \\
\hline & ASOCIACIÓN III & [voto] \\
\hline & MUNICIPALIDAD DE LOS ÁlAMOS & \\
\hline & SINDICATO & \\
\hline & ASOCIACIÓN DE ADMINISTRATIVOS & \\
\hline & ACEVEDO II & \\
\hline & CASTILlO & \\
\hline & FRIES & \\
\hline & CONFEDERACIÓN II & \\
\hline & MOYA & \\
\hline & ASOCIACIÓN GREMIAL & \\
\hline & DELGADO & \\
\hline & ASOCIACIÓN DE ENFERMERAS & \\
\hline & TRONCOSO & \\
\hline & CARREÑO & \\
\hline & FEDERACIÓN DE ASOCIACIONES & \\
\hline & NEIRA & [voto] \\
\hline
\end{tabular}


Gráfico 10.2. Conducta de los ministros y abogados integrantes: Legitimación activa para ejercer la acción de protección

\begin{tabular}{|c|c|c|c|c|}
\hline \multirow[b]{2}{*}{ AÑo } & \multirow[b]{2}{*}{ CASO } & \multicolumn{3}{|c|}{ EL RECURSO DE PROTECCIÓN NO CONSTITUYE UNA ACCIÓN POPULAR } \\
\hline & & \multicolumn{2}{|c|}{$\begin{array}{l}\text { EXIGE UN GRADO DE DETERMINACIÓN MÁS ESTRICTO } \\
\text { RESPECTO A LA INDIVIDUALIZACIÓN DEL AFECTADO }\end{array}$} & \begin{tabular}{|c|} 
EXIGE UN GRADO DE DETERMINACIÓN MENOS ESTRICTO \\
RESPECTO A LA INDIVIDUALIZACIÓN DEL AFECTADO \\
\end{tabular} \\
\hline \multirow{61}{*}{2020} & REY & [S. Muñoz][Viva & anco][Llanos][Mera][Barra] & \\
\hline & PARTIDO RADICAL & [S. Muńoz][Vive & anco][Sandoval][Quintanilla][Pallavicini] & \\
\hline & MUÑOZ I & [Viva & anco][Sandoval][Pierry][PPallavicini] & [S. Muñoz] \\
\hline & VIDAL & [S. Muñoz][Viva & anco][Sandoval][Pierry][Pallavicini] & \\
\hline & VALENZUELA & [S. Muñoz][Viva & anco][Sandoval][Quintanilla][Lagos] & \\
\hline & PÉREZ & [S. Muñoz][Viva & anco][Sandoval][Quintanilla][Pallavicini] & \\
\hline & SCAFF I & [S. Muñoz][Viva & anco][Sandoval][Pierry][Etcheberry] & \\
\hline & SCAFF II & [S. Muñoz][Viva & anco][Sandoval][Pierry][Etcheberry] & \\
\hline & LOBOS & [S. Muñoz][Viva & anco][Sandoval][Pierry][Etcheberry] & \\
\hline & MUNICIPALIDAD DE CALDERA & [S. Muñoz][Viva & anco][Sandoval][Aránguiz][Pallavicini] & \\
\hline & ASOCIACIÓN I & [S. Muñoz][Vive & anco][Sandoval][Quintanilla][Lagos] & \\
\hline & FEDERACIÓN & [S. Muñoz][Viva & anco][Sandoval][Quintanilla][Lagos] & \\
\hline & ALMONACID & [S. Muñoz][Viva & anco][Sandoval][Quintanilla][Lagos] & \\
\hline & GONZÁLEZ & [S. Muñoz][Viva & anco][Sandoval][Quintanilla][Lagos] & \\
\hline & SCAFF III & [S. Muñoz][Viva & anco][Sandoval][Quintanilla][Lagos] & \\
\hline & BARUDY & [S. Muñoz][Viva & anco][Sandoval][Quintanilla][[Munita] & \\
\hline & CONFEDERACIÓN I & [S. Muñoz][Viva & anco][Sandoval][Quintanilla][[Munita] & \\
\hline & MUNICIPALIDAD PADRE LAS CASAS & [S. Muñoz][Viva & anco][Sandoval][Quintanilla][[Munita] & \\
\hline & UNIVERSIDAD & [S. Muñoz][Viva & anco][Sandoval][Quintanilla][[Munita] & \\
\hline & CRISTI I & [S. Muñoz][Viva & anco][Sandoval][Quintanilla][[Munita] & \\
\hline & CONFEDERACIÓN DEMOCRÁTICA I & [S. Muñoz][Viva & anco][Sandoval][Quintanilla] $][$ Munita] & \\
\hline & PEZO & [S. Muñoz][Viva & anco][Sandoval][Quintanilla][[Munita] & \\
\hline & CABALLERO & [S. Muñoz][Viva & anco][Sandoval][Quintanilla][[Munita] & \\
\hline & MUNICIPALIDAD DE CERRO NAVIA & [S. Muñoz][Viva & anco][Sandoval][Quintanilla][[Munita] & \\
\hline & MuÑOZ II & [S. Muñoz][Viva & anco][Sandoval][Quințánilla][Pallavicini] & \\
\hline & REBOLLEDO & [S. Muñoz][Viva & anco][Sandoval][Gómez][Abuauad] & \\
\hline & MUNICIPALIDAD DE LUMACO & [S. Muñoz][Viva & anco][Sandoval][Gómez][Abuauad] & \\
\hline & SINDICATO & [S. Muñoz][Viva & anco][Sandoval][Gómez][Abuauad] & \\
\hline & CRISTI II & [S. Muñoz][Viva & anco][Sandoval][Gómez][Abuauad] & \\
\hline & ORTEGA & [S. Muñoz][Viva & anco][Sandoval][Gómez][Abuauad] & \\
\hline & ASOCIACIÓN DE FUNCIONARIOS & [S. Muñoz][Viva & anco][Sandoval][Gómez][Abuauad] & \\
\hline & CORPORACIÓN & [S. Muñoz][Viva & anco][Sandoval][Gómez][Abuauad] & \\
\hline & FEDERACIÓN METROPOLITANA & [S. Muñoz][Viva & anco][Sandoval][Gómez][Lagos] & \\
\hline & CERDA & [S. Muñoz][Viva & anco][Sandoval][Gómez][Lagos] & \\
\hline & CONFEDERACIÓN DEMOCRÁTICA II & [S. Muñoz][Vivà & anco][Sanđ̧ôval][Gómez][Lagos] & \\
\hline & ASOCIACIÓN II & [S. Muñoz][Vivā̄ & ânco][Sandoval][Gómez][Lagos] & \\
\hline & HIRSCH & [S. Muñoz][Viva & anco][Sandoval][Gómez][Lagos] & \\
\hline & SINDICATO & [S. Muñoz][Viva & anco][Sandoval][Gómez][Abuauad] & \\
\hline & MUÑOZ III & [S. Muñoz][Viva & anco][Sandoval][Lagos][Pallavicini] & \\
\hline & INDH & [S. Muñoz][Viva & anco][Sandoval][Lagos][Pallavicini] & \\
\hline & BARRÍA & [S. Muñoz][Viva & anco][Sandoval][Lagos][Pierry] & \\
\hline & GARCÍA DE LA PASTORA & [S. Muñoz][Viva & anco][Sandoval][Lagos][Pierry] & \\
\hline & ACEVEDO I & [S. Muñoz][Viva & anco][Sandoval][Pierry][Pallavicini] & \\
\hline & JUNTA DE VECINOS & [S. Muñoz][Viva & anco][Sandoval][Pierry][Pallavicini] & \\
\hline & PEÑA & [S. Muñoz][Vive. & anco][Sandoval][Pierry][Pallavicini] & \\
\hline & ASOCIACIÓN III & [Viva & anco][Sandoval][Pierry][Dahm] & [S.Muñoz] \\
\hline & MUNICIPALIDAD DE LOS ÁLAMOS & [S. Muñoz][Viva & anco][Sandoval][Quintanilla][Lagos] & \\
\hline & SINDICATO & [S. Muñoz][Viva & anco][Sandoval][Quintanilla][Pallavicini] & \\
\hline & ASOCIACIÓN DE ADMINISTRATIVOS & [S. Muñoz][Viva & anco][Sandoval][Pierry][Pallavicini] & \\
\hline & ACEVEDO II & [S. Muñoz][Viva & anco][Sandoval][Pierry][Zepeda] & \\
\hline & CASTILlO & [S. Muñoz][Viva & anco][Sandoval][Pierry][Pallavicini] & \\
\hline & FRIES & [S. Muñoz][Viva & anco][Sandoval][Lagos][Pierry] & \\
\hline & CONFEDERACIÓN II & [Repetto] [Viva & anco][Sandoval][Quintanilla][Pallavicini] & \\
\hline & MOYA & [Repetto] [Viva & anco][Sandoval][Quintanilla][Pallavicini] & \\
\hline & ASOCIACIÓN GREMIAL & [Repetto] [Viva & anco][Sandoval][Quintanilla][Pallavicini] & \\
\hline & DELGADO & [J. Muñoz] [Viva & anco][Sandoval][Lagos]][Pierry] & \\
\hline & ASOCIACIÓN DE ENFERMERAS & [S. Muñoz][Viva & anco][Sandoval][Llanos][Zepeda] & \\
\hline & TRONCOSO & [Pierry] [Viva & anco][Sandoval][Quintanilla][Dahm] & \\
\hline & CARREÑO & [S. Muñoz][Viva & anco][Sandoval][Pierry][Ravanales] & \\
\hline & FEDERACIÓN DE ASOCIACIONES & [S. Muñoz][Vive & anco][Sandoval][Pierry][Ravanales] & \\
\hline & NEIRA & [Viva & anco][Sand $\rho$ val][Pierry][Llanos] & [S.Muñoz] \\
\hline
\end{tabular}


Gráfico 12.1. Comportamiento de la sala: Régimen de los funcionarios a honorarios y supletoriedad del Código del Trabajo

\begin{tabular}{|c|c|c|c|}
\hline AÑ̃o & $\begin{array}{l}\text { CASOS QUE NO APLICAN EL } \\
\text { CÓDIGO DEL TRABAJO }\end{array}$ & $\begin{array}{l}\text { CASOS QUE DISTINGUEN LA } \\
\text { NATURALEZA DEL VÍNCULO, } \\
\text { APLICANDO EL CT Y EL EA, } \\
\text { SEGÚN CORRESPONDA }\end{array}$ & $\begin{array}{c}\text { CASOS QUE APLICAN EL CódIGo } \\
\text { CIVIL }\end{array}$ \\
\hline \multirow[t]{29}{*}{2020} & MALDONADO & [voto] & \\
\hline & TABILO & [voto] & \\
\hline & VALDEBENITO & [voto] & \\
\hline & CARRASCO & [voto] & \\
\hline & TAPIA & & \\
\hline & ARAVENA & & \\
\hline & & AYANCÁN & \\
\hline & PALOMERA & [voto] & \\
\hline & ÁLVAREZ & & \\
\hline & PÉREZ & [voto] & \\
\hline & GUISTINI & [voto] & \\
\hline & NAGUIL & [voto] & \\
\hline & CARRASCO & [voto] & \\
\hline & & POBLETE & \\
\hline & JEREZ & [voto] & \\
\hline & VALDÉS & & \\
\hline & PINTO & & \\
\hline & CERDA & & \\
\hline & & ALDANA & \\
\hline & & VARGAS & \\
\hline & CORRIAL & & \\
\hline & CARRILLO & & \\
\hline & UTRERAS & & \\
\hline & ESPINOZA & & \\
\hline & CONTARDO & & \\
\hline & ORELLANA & [voto] & \\
\hline & FUENTES & [voto] & \\
\hline & LEPE & [voto] & \\
\hline & & & (C) PDAE UC 2021 \\
\hline
\end{tabular}

Gráfico 12.2. Conducta de ministros y abogados integrantes: Funcionarios a honorarios y supletoriedad del Código del Trabajo

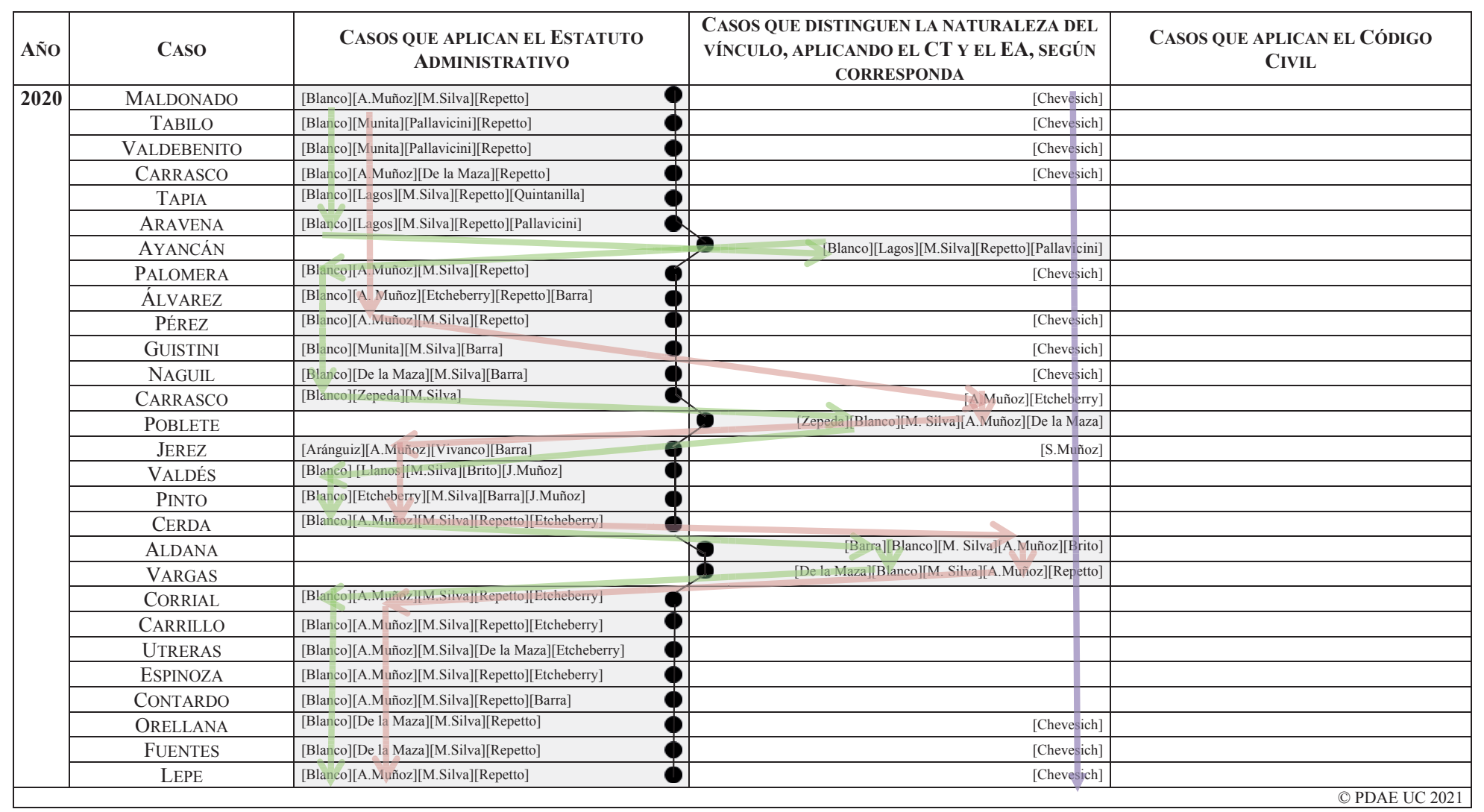


Gráfico 13.1. Comportamiento de la sala: Término anticipado de empleo a contrata

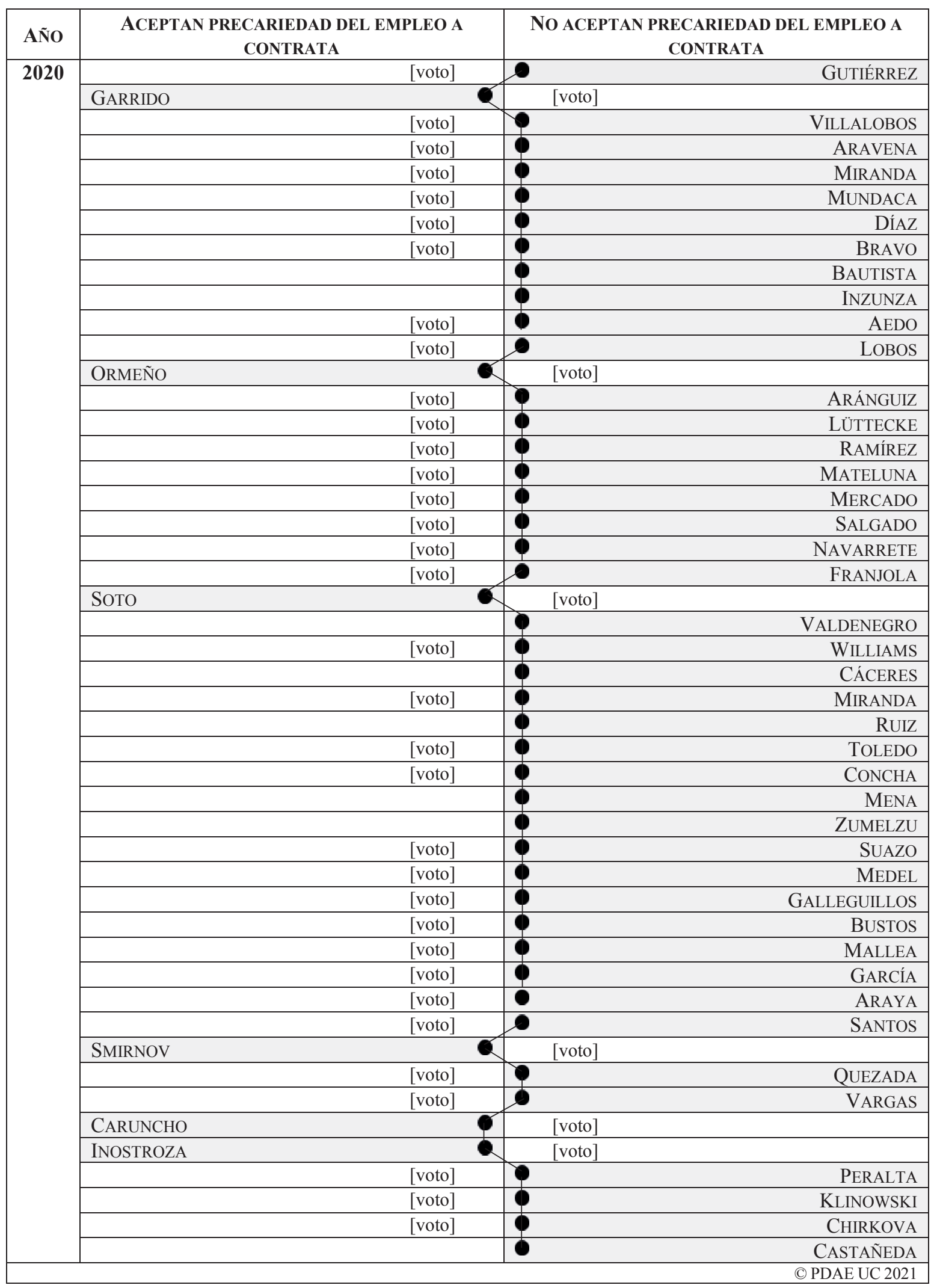


Gráfico 13.2. Comportamiento de los ministros: Término anticipado de empleo a contrata

\begin{tabular}{|c|c|c|c|c|c|}
\hline \multirow{49}{*}{$\begin{array}{l}\text { AÑO } \\
2020\end{array}$} & Caso & \multirow{2}{*}{\multicolumn{2}{|c|}{$\begin{array}{l}\text { ACEPTAN PRECARIEDAD DEL EMPLEO A CONTRATA } \\
\text { [Aránguiz][Barra] }\end{array}$}} & \multicolumn{2}{|c|}{ NO ACEPTAN PRECARIEDAD DEL EMPLEO A CONTRATA } \\
\hline & GUTIÉRREZ & & & \multirow{2}{*}{\multicolumn{2}{|c|}{$\begin{array}{r}\text { [Sandoval][Lagos][Prado] } \\
{[\text { Aránguiz][Barra }}\end{array}$}} \\
\hline & GARRIDO & \multirow{2}{*}{\multicolumn{2}{|c|}{ [Sandoval][Lagos][Prado] }} & [Aránguiz][Barra] & \\
\hline & VILLALOBOS & [Pierry] & & 0 & [Quintanilla][Sandoval][Aránguiz][S.Muñoz] \\
\hline & ARAVENA & \multicolumn{2}{|c|}{ [Sandoval][Pallavicini] } & 0 & [Quintanilla][Prado][S.Mu \\
\hline & MIRANDA & & e & [Quintanilla][Sandoval][Prado][S.Mu hoz] \\
\hline & MUNDACA & \multicolumn{2}{|l|}{ [Sandoval] } & 0 & [Gómez][Lagos][Vivanco][S.Muloz] \\
\hline & DÍAZ & \multicolumn{2}{|l|}{ [Pallavicini] } & 0 & [Quintanilla][J.Muñoz][Vivanco][S.Muñoz] \\
\hline & BRAVO & \multicolumn{2}{|l|}{ [Pallavicini] } & 0 & [Quintanilla][J.Muñoz][Vivanco][S.Munoz] \\
\hline & BAUTISTA & \multirow{3}{*}{ [Sandoval] } & & 0 & [Barra][Munita][Biel][Vivanco][S.Mu ouz] \\
\hline & INSUNZA & & & 0 & [Barra][Munita][Biel][Vivanco][S.Muhoz] \\
\hline & AEDO & & & 0 & [Gómez][Lagos][Vivanco][S.Munoz] \\
\hline & LOBOS & \multicolumn{2}{|c|}{ [Sandoval][Pallavicini] } & 0 & [J.Muñoz][Vivănco][S.Mu oz] \\
\hline & ORMEÑO & \multicolumn{2}{|c|}{ [Pallavicini][Pierry][Vivanco] } & & [Aránguiz][S.Munoz] \\
\hline & ARÁNGUIZ & [Pierry] & & 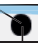 & [Quintanilla][I.Muñoz][Vivanco][S.Mu \\
\hline & LÜTTECKE & [Pierry] & & 0 & [Quintanilla][J.Muñoz][Vivanco][S.Mu oz] \\
\hline & RAMÍREZ & [Pierry] & & 0 & [Quintanilla][J.Muñoz][Vivanco][S.Mu oz] \\
\hline & MATELUNA & [Sandoval][Pallav & vicini] & 0 & [J.Muñoz][Vivanco][S.Munoz] \\
\hline & MERCADO & \multicolumn{2}{|c|}{ [Sandoval][Pallavicini] } & 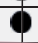 & [J.Muñoz][Vivanco][S.Munoz] \\
\hline & SALGADO & [Palla & vicini] & 0 & [Quintamilla][Sandoval][Prado][S.Mu oz] \\
\hline & NAVARRETE & [Palla & vicini] & 0 & [Llanos][Sandova]][Vivanco][S.Munoz] \\
\hline & FRANJOLA & [Palla & vicini] & 9 & [Aränguiz][Sandoval][Vivanco][S.Mu ouz] \\
\hline & SOTO & [Sandoval][Pailia & vicini][Vivanco] & & [Llanos][S.Munoz] \\
\hline & VALDENEGRO & & & 8 & [Barra][Quintanilla][Zepeda][Llanos][S.Munoz] \\
\hline & WILLIAMS & [Quint & anilla][Vivañico] & 0 & [Repetto][Llanos][S.Munoz] \\
\hline & CÁCERES & & & 0 & [Barra][Quintanilla][Zepeda][Llanos][S.Munoz] \\
\hline & MIRANDA & [Palla & vicini][Quintanilla] & & [Zepeda][Llanos][Aránguiz] \\
\hline & RUIZ & & & 0 & [Barra][Quintanilla][Zepeda][Llanos][S.Mu oz \\
\hline & TOLEDO & [Sandoyal][Pierr? & & 0 & [Llanos][Vivanco][S.Muhoz] \\
\hline & CONCHA & [Sandoval][Palla & vicini] & 0 & [Llanos][Vivanco][S.Muñoz] \\
\hline & MENA & & & 8 & [Quintanilla][Repetto][Llanos][Vivanco][S.Mu \\
\hline & ZUMELZU & & & 0 & [Etcheberry][Sandoval][Llanos][Vivanco][S.Muhoz] \\
\hline & SUAZO & [Pallar & icini] & 0 & [Sandoval][Llanos][Vivanco][Lagos] \\
\hline & MEDEL & [Sandoval] & & 0 & [Aránguiz][Llanos][Vivanco][S.Muñoz] \\
\hline & GALLEGUILLOS & [Pallar & icini][Pierry] & 0 & [Llanos][Vivanco][S.Munoz] \\
\hline & BUSTOS & [Pierry] & & 0 & [Gómez][Zepeda][Llanos][S.Muloz] \\
\hline & MALLEA & [Sandoval][Palla & ieini] & 0 & [Etcheberry][Zepeda][S.Munoz] \\
\hline & GARCÍA & [Palla & vicini] & 0 & [Quintanilla][Sandoval][Vivanco][S.Munoz] \\
\hline & ARAYA & [Sandoval][Palla: & icini] & - & [Gómez][Zepeda][S.Munoz] \\
\hline & SANTOS & [Palla & vicini] & e & [Pierry][SSandoval][Vivanco][S.Muñoz] \\
\hline & SMIRNOV & [Sandoval][Vivel] & Wou][Lagos][Eicheberiy] & & [S.Muñoz] \\
\hline & QUEZADA & [Sandoval][Palla & vicini] & - & [Llanos][Vivanco][S.Muñoz] \\
\hline & VARGAS & [Sandoval][Palla & vicini] & 0 & [Pierry][Vivanco][S.Muñoz] \\
\hline & CARUNCHO & [Sandoval][Palla & vicini][Vivanco] & & [Repetto][Quintanifila] \\
\hline & INOSTROZA & [Sandopval][Rava & nales][Vivanco][Quintanilla] & & [S.Muñoz] \\
\hline & PERALTA & [Sandoval] & & 0 & [Quintanilla][Biel][Vivanco][S.Muñoz] \\
\hline & KLINOWSKI & [Sandoyal] & & 0 & [Pierry][Abuauad][Vivanco][S.Munoz] \\
\hline & CHIRKOVA & [Sandoval] & & 0 & [Pierry][Abuauad][Vivanco][S.Mụpoz] \\
\hline & CASTAÑEDA & & & 0 & [Abuauad][Quintanilla][Biel][Vivanco][Sandoval] \\
\hline & & & & & (c) PDAE UC 2021 \\
\hline
\end{tabular}

Gráfico 14.1. Comportamiento de la sala: Desviación de poder en las desvinculaciones de funcionarios a contrata

\begin{tabular}{|c|l|c|c|}
\hline \multirow{3}{*}{ AÑo } & $\begin{array}{c}\text { RECONOCE DESVIACIÓN DE PODER COMO VICIO DE } \\
\text { LEGALIDAD EN LAS DESVINCULACIONES/TRASLADOS DE } \\
\text { FUNCIONARIOS }\end{array}$ & $\begin{array}{c}\text { DESCONOCE DESVIACIÓN DE PODER COMO VICIO DE } \\
\text { LEGALIDAD EN LAS DESVINCULACIONES/TRASLADOS DE } \\
\text { FUNCIONARIOS }\end{array}$ \\
\hline \multirow{2}{*}{2020} & GÁLVEZ & & {$[\mathrm{voto}]$} \\
\cline { 2 - 4 } & CASTILLO & {$[\mathrm{voto}]$} \\
\cline { 2 - 4 } & GÓMEZ & \\
\cline { 2 - 4 } & MÜLLER & P PDAE UC 2021 \\
\hline
\end{tabular}

Gráfico 14.2. Comportamiento de ministros y abogados integrantes: Desviación de poder en las desvinculaciones de funcionarios a contrata

\begin{tabular}{|c|c|c|c|}
\hline AÑ̃o & CASO & $\begin{array}{l}\text { RECONOCE DESVIACIÓN DE PODER COMO VICIO DE } \\
\text { LEGALIDAD EN LAS DESVINCULACIONES/TRASLADOS DE } \\
\text { FUNCIONARIOS }\end{array}$ & $\begin{array}{l}\text { DESCONOCE DESVIACIÓN DE PODER COMO VICIO DE } \\
\text { LEGALIDAD EN LAS DESVINCULACIONES/TRASLADOS DE } \\
\text { FUNCIONARIOS }\end{array}$ \\
\hline \multirow[t]{4}{*}{2020} & GÁLVEZ & [Lagos] [Vivānco][Sandōval][Llanos][Pallavicini] & \\
\hline & CASTILO & [S.Muñoz][Vivanco][Sandoval][Pierry] & [Pạllavicini] \\
\hline & GÓMEZ & [S.Muñoz][Vivananco][Sandoval][Pierry] & [Pallavicini] \\
\hline & MÜLLER & [S.Muñoz][Zepeda][Barra][Quintanilla][Llanos] & \\
\hline
\end{tabular}


Gráfico 15.1. Comportamiento de la sala: Recurso de protección como vía idónea en casos de desvinculación de funcionarios a contrata

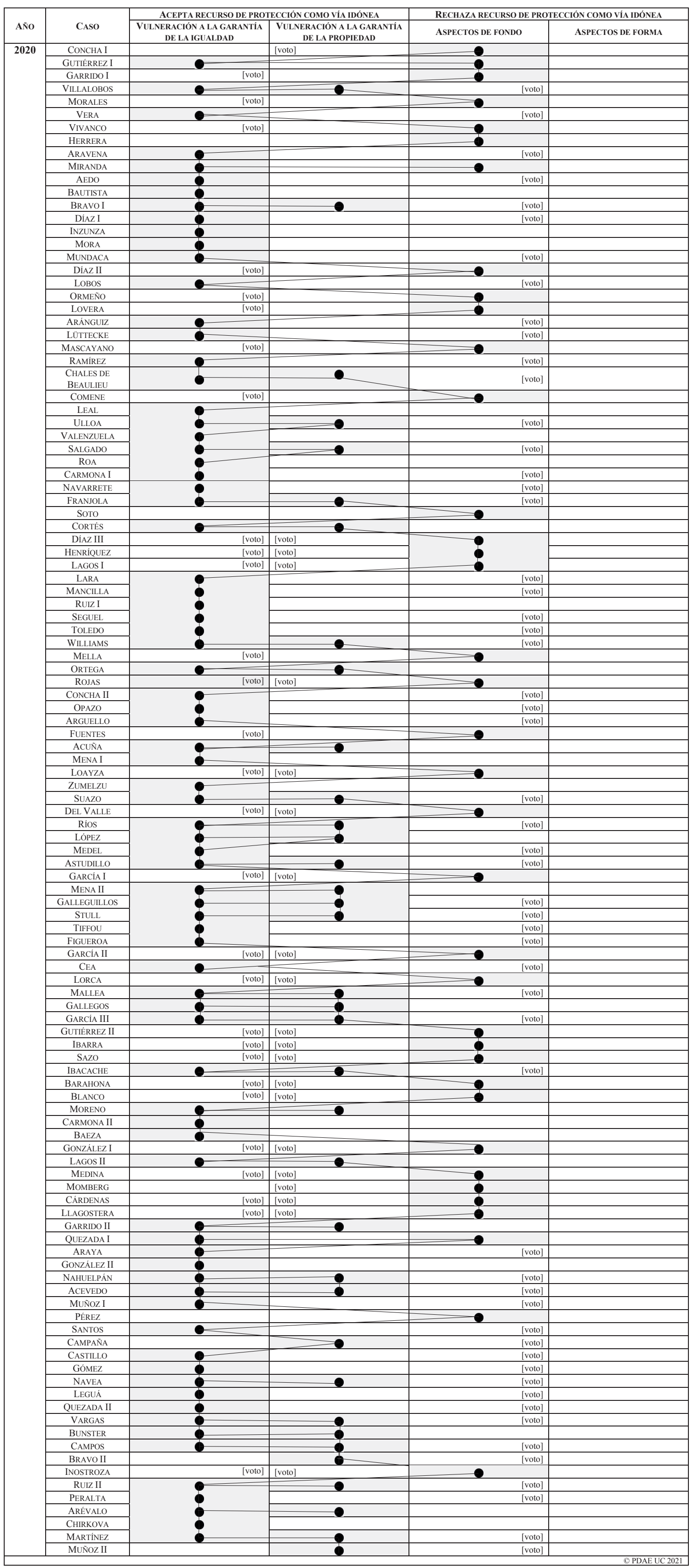


Gráfico 15.2. Comportamiento de ministros y abogados integrantes: Recurso de protección como vía idónea en casos de desvinculación de funcionarios a contrata

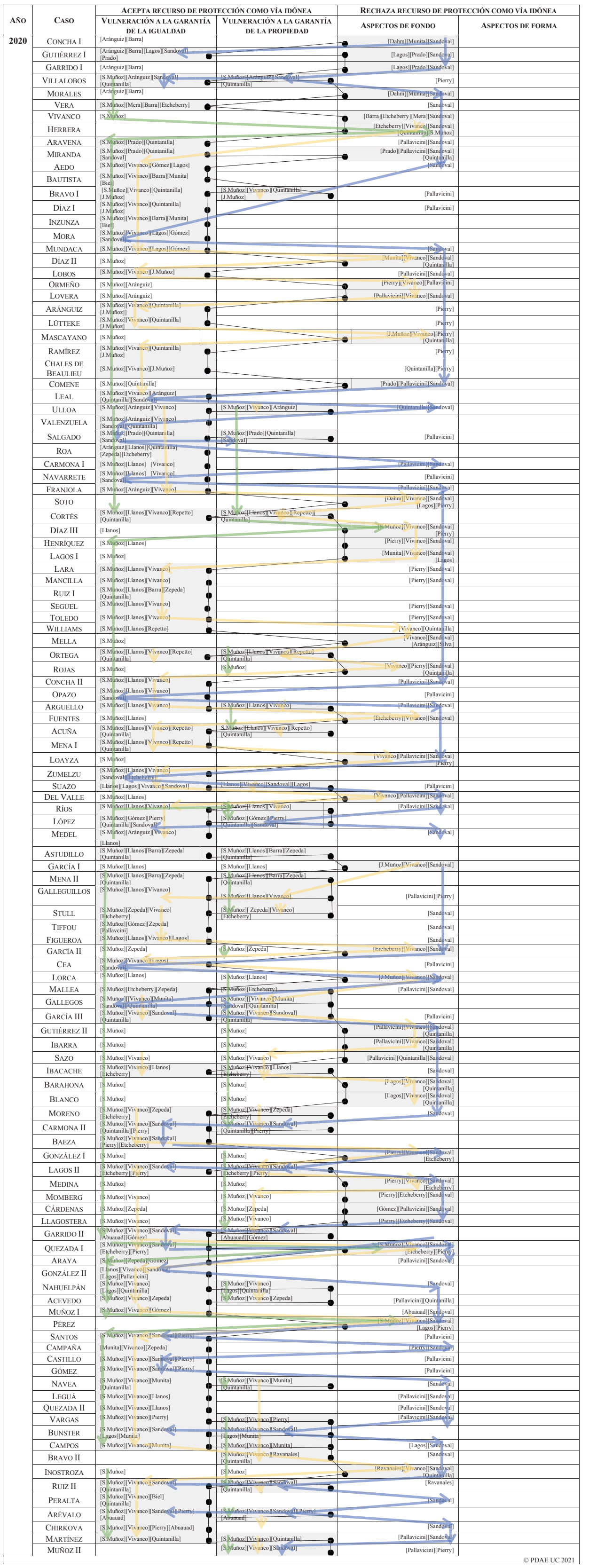


Gráfico 16.1. Comportamiento de la sala: Regularización de derechos de aguas

\begin{tabular}{|c|c|c|}
\hline AÑo & ACEPTANDO & RECHAZANDO \\
\hline \multirow[t]{11}{*}{2020} & FLORES I & [voto] \\
\hline & FLORES II & [voto] \\
\hline & FLORES III & [voto] \\
\hline & HUANCA I & [voto] \\
\hline & HUANCA II & [voto] \\
\hline & AGRÍCOLA & [voto] \\
\hline & PARRAO & \\
\hline & [voto] & META \\
\hline & MULET & [voto] \\
\hline & COMERCIAL & \\
\hline & GONZÁLEZ & [voto] \\
\hline
\end{tabular}

Gráfico 16.2. Comportamiento de ministros y abogados integrantes: Regularización de derechos de aguas

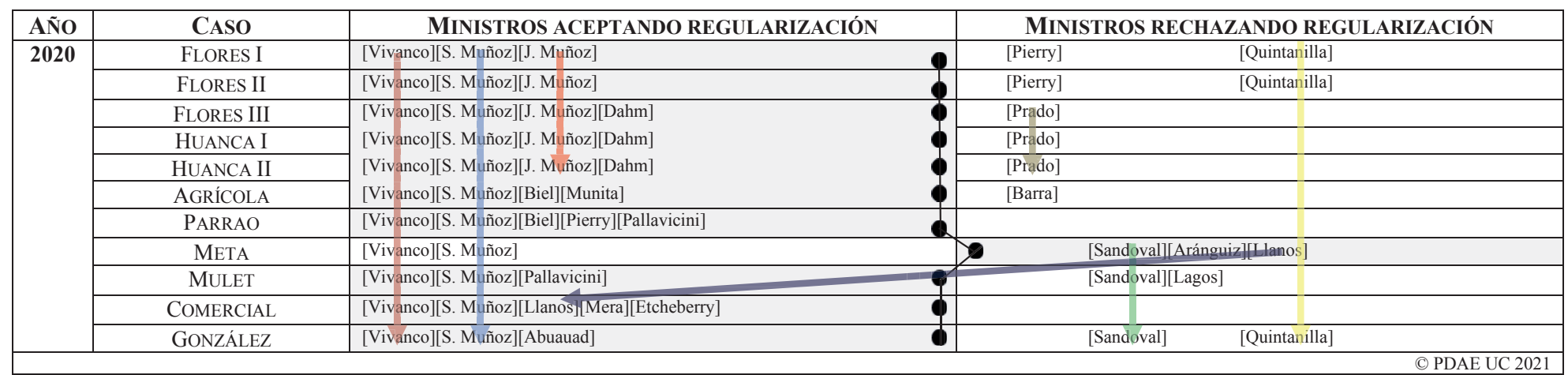

Gráfico 17.1. Comportamiento de la sala: Autorización como requisito de servidumbres mineras

\begin{tabular}{|c|l|c|}
\hline AÑo & EXIGE SÓlO REQUiSITOS DE LA LEGISLACIÓN MINERA & EXIGE REQUiSITOS QUE NO SON DE LA LEGISLACIÓN MINERA \\
\hline 2020 & MUÑOZ & [voto] \\
\hline \multicolumn{2}{|r}{} \\
\hline
\end{tabular}

Gráfico 17.2. Conducta de ministros y abogados integrantes: Autorizaciones como requisitos de servidumbres mineras

\begin{tabular}{|c|c|l|r|}
\hline AÑo & CASO & EXIGE SÓLO REQUISITOS DE LA LEGISLACIÓN MINERA & EXIGE REQUISITOS QUE NO SON DE LA LEGISLACIÓN MINERA \\
\hline $\mathbf{2 0 2 0}$ & MUÑOZ & [A. Muñoz][Repetto][Chevesich][De la Maza] & [Blanco] \\
\hline
\end{tabular}

Gráfico 18.1. Comportamiento de la sala: Plazo para que tercero absoluto pueda solicitar invalidación ambiental

\begin{tabular}{|c|c|cr|}
\hline AÑo & APLICA PLAZO DE DOS AÑOS & APLICA PLAZO DE TREINTA DÍAS \\
\hline $\mathbf{2 0 2 0}$ & {$[\mathrm{voto}]$} & STIPICIC \\
\hline
\end{tabular}

Gráfico 18.2. Comportamiento de ministros y abogados integrantes: Plazo para que tercero absoluto pueda solicitar invalidación ambiental

\begin{tabular}{|c|c|c|r|}
\hline AÑo & CASO & APLICA PLAZO DE DOS AÑOS & APLICA PLAZO DE TREINTA DÍAS \\
\hline $\mathbf{2 0 2 0}$ & STIPICIC & [S. Muñoz][Vivanco] & [Sandoval][Aránguiz][Prado] \\
\hline \multicolumn{2}{|l|}{} \\
\hline
\end{tabular}




\section{Conclusiones}

\section{Resultados distintos en 2020}

El resultado de la revisión de la jurisprudencia de la Corte Suprema, en veinte temas en 2020 (en los 17 temas en que se registraron fallos, efectivamente), en cuanto a su uniformidad o vacilación es distinto al de los estudios anteriores, que cubrieron la década anterior (2008 a 2018) y 2019. La jurisprudencia resultante es cada vez más lineal en cuanto a las sentencias que emiten las salas de la CS. En cuanto a la conducta de sus ministros y abogados integrantes, también tiende más a la linealidad pero persisten zigzagueos individuales y otros de la propia Sala (originados estos últimos usualmente por un cambio de integración de dicha Sala o por el cambio de voto de algún ministro o abogado integrante). La Corte Suprema, entonces, en general sigue exhibiendo una nueva conducta contrastada: por una parte, dirigida a ofrecer precedentes, pues se aprecia un aumento de temas con jurisprudencia uniforme; pero, no obstante, paralelamente, se mantienen las vacilaciones en algunos otros temas.

\section{Comportamiento de las salas: tres conductas se aprecian}

Podemos esquematizar la conducta de las Salas de la CS así: i) hay temas en que la jurisprudencia de la década anterior era lineal, y sigue siéndolo (no se aprecia la conducta inversa: que antes fuese lineal y ahora sea zigzagueante); ii) hay temas en que la jurisprudencia en la década anterior era zigzagueante y ahora es lineal; esto es, la CS deja de zigzaguear; y, iii) hay temas en que la jurisprudencia era zigzagueante y sigue siéndolo. Se puede apreciar en los gráficos respectivos. El resumen es el siguiente:

a) Temas en que la jurisprudencia sigue siendo lineal. Hay temas en que la jurisprudencia fue uniforme en períodos anteriores y sigue siéndolo en 2020. Es el caso de los siguientes temas: 1 (cómputo de plazos); 6 (prescripción acción nulidad); 8 (prescripción acción de responsabilidad.

b) Temas en que la jurisprudencia ahora es uniforme. Hay temas en que la jurisprudencia fue zigzagueante en los períodos anteriores y deja de serlo en 2020. Es el caso de los siguientes temas: 2 (plazos fatales); 4 (plazo acción sancionatoria), el cual ya había dado señales de uniformidad durante 2019; 5 (agotamiento vía administrativa), que es uniforme desde el año 2012, 7 (cómputo plazos), en que se sostiene un criterio lineal desde 2018; 9 (indemnización por responsabilidad crímenes lesa humanidad), uniforme desde el año 2015; 10 (legitimación activa), con postura lineal desde 2018; 14 (desviación de poder); y 17 (autorización como requisito de servidumbre minera), el cual viene siendo uniforme desde 2017.

c) Temas en que la jurisprudencia continúa zigzagueando, o empieza a zigzaguear. Hay temas en que la jurisprudencia sigue zigzagueando, o bien se incurre por primera vez en zigzag. Así: i) comienza a zigzaguear en el tema 3 (audiencia previa en invalidación), en el cual la CS había sostenido un crite- 
rio lineal hasta 2019, sin embargo en 2020 incurrió en un zigzag; y, ii) sigue zigzagueando en los siguientes temas: 12 (funcionarios a honorarios); 13 (contratas); 15 (protección como vía idónea); 16 (regularización derechos aguas) y 18 (invalidación ambiental).

d) Temas en que no hubo casos durante el año 2020. Tal situación se produjo en los temas 11 (acción mera certeza); 19 (afectación presunta); y 20 (acceso a playas públicas). En los temas 11 y 20, la jurisprudencia anterior había sido vacilante; en el tema 20 había sido uniforme.

En suma, puede decirse que, durante 2020, ha habido un retroceso en la uniformidad de la jurisprudencia pues han aumentado los temas en los que lamentablemente se mantiene el zigzagueo.

\section{Comportamiento de ministros y abogados integrantes en 2020}

Si bien en algunos temas se mantiene una linealidad de las salas, lo que se debe a una conducta más lineal de sus ministros y abogados integrantes, también se mantienen algunas conductas erráticas de algunos de ellos. Al respecto, podemos observar tres tipos de conductas de ministros y abogados integrantes (las que se pueden apreciar en los gráficos respectivos): i) casos de ministros y abogados integrantes que anteriormente eran muy zigzagueantes, si bien ahora siguen zigzagueando, lo hacen en menos ocasiones; ii) hay ministros y abogados integrantes que anteriormente eran levemente zigzagueantes, tienden a ofrecer conductas más lineales; y, iii) son minoritarios los ministros que ofrecen gran linealidad y uniformidad en sus votos. Este comportamiento puede comprobarse en los gráficos y antecedentes del Estudio.

\section{Resumen de los resultados que arroja el Estudio del año 2020}

En el primer estudio, que cubrió desde 2008 a 2018, mostramos una alta vacilación de la CS. Luego, en el año 2019 hubo una leve mejoría, ello quizás fue una reacción transitoria ante la publicación de nuestro Estudio; pero el año 2020 hubo un retroceso. De las cifras, descontando los tres temas en que no hubo pronunciamientos en 2020, podemos comprobar que: i) solo en tres de los veinte temas la CS ha sido siempre lineal, desde 2008 a 2020; ii) existen ocho temas en que hubo una reacción positiva de la CS a partir de 2019 y 2020: antes era zigzagueante y ahora es lineal; y iii) pero se mantienen otros seis temas de la muestra, bien relevantes, en que aún existen conductas zigzagueantes tanto de ministros y abogados integrantes, como de las Salas. 


\section{Anexo de sentencias [Total de casos: 329 casos]}

\section{Conflictos durante el procedimiento administrativo}

\section{Cómputo de plazos durante la tramitación del procedimiento administrativo [6 casos]}

Televisión Nacional de Chile (2020): CS, 27 enero 2020 (Rol N²0896-2019), 3a Sala. M: Sandoval, Aránguiz, Vivanco, Repetto, Biel (r) [queja].

Caltec SPA con Secretaría Regional Ministerial de Salud Región de Antofagasta (2020): CS, 9 marzo 2020 (Rol N² 25021-2018), 3a Sala. M: S. Muñoz, Sandoval, Aránguiz (r), Vivanco; Al: Etcheberry [casación].

Antofagasta Minerals con Secretaría Regional Ministerial de Salud de Atacama (2020): CS, 8 junio 2020 (Rol N²9791-2018), 3a Sala. M: S. Muñoz (r), Sandoval, Aránguiz, Vivanco; Al: Munita [casación].

Security Event SpA (2020): CS, 28 agosto 2020 (Rol No 30168-2020), 3a Sala. M: S. Muñoz (d) (r), Sandoval, Dahm, Vivanco; Al: Pierry [queja].

Ortega González, Oscar con Cristi Marfil, Oscar (2020): CS, 26 octubre 2020 (Rol No 129375-2020), 3a Sala. M: S. Muñoz, Sandoval, Vivanco, Ravanales; Al: Pierry [s/r] [apelación].

Enel Distribución Chile S.A. con Superintendencia de Electricidad y Combustibles (2020): CS, 1 diciembre 2020 (Rol No 138642-2020), 3a Sala. M: S. Muñoz, Sandoval, Vivanco; Al: Pierry, Abuauad [s/r] [apelación].

2. Plazos fatales para que la Administración responda solicitudes del ciudadano [5 casos]

KDM S.A con Secretaría Regional Ministerial de Salud Región Metropolitana (2020): CS, 5 mayo 2020 (Rol Nº 6704-2019), 3a Sala. M: S. Muñoz (p), A. Muñoz (r), Vivanco, Repetto, Biel [casación].

Industrial Textil Mejillones S.A con Flies Añon, Jorge (2020): CS, 23 junio 2020 (Rol No 17374-2019), 3a Sala. M: S. Muñoz, Prado, Llanos; Al: Pallavicini, Pierry (r) [casación].

Velásquez Sánchez, Nestor con Superintendencia de Valores y Seguros (2020): CS, 31 julio 2020 (Rol N² 29982-2019), 3a Sala. M: S. Muñoz (p), Sandoval, Vivanco; Al: Quintanilla (r), Lagos [reclamación].

Carrillo Schneider, Alfonso con Dirección General de Aguas (2020): CS, 12 agosto 2020 (Rol N 13796-2019), 3a Sala. M: S. Muñoz, Sandoval, Vivanco; Al: Pallavicini, Pierry (r) [casación].

Reyes Tapia, Patricio con Zarhi Troy, Andrés (2020): CS, 9 octubre 2020 (Rol № 97284 2020), 3a Sala. M: Sandoval, Prado, Vivanco; Al: Munita (r), Pallavicini (p) [protección].

3. Audiencia previa como requisito esencial del procedimiento de invalidación [7 casos]

Del Pino Villarreal, Bárbara con Servicio de Salud del Reloncavi (2020): CS, 9 marzo 2020 (Rol N²3276-2019), 3a Sala. M: S. Muñoz, Sandoval, Aránguiz, Vivanco (r); Al: Etcheberry [protección].

Coexca S.A. con Navarro Pereira, Mario (2020): CS, 29 mayo 2020 (Rol N³0013-2019), 3a Sala. M: Sandoval, Vivanco (r), Llanos; Al: Lagos, Pallavicini [protección].

Sepúlveda Fuentes, Jorge con Ilustre Municipalidad de San Javier (2020): CS, 19 junio 2020 (Rol N 30011-2019), 3a Sala. M: S. Muñoz, Sandoval, Vivanco (r), Zepeda; Al: Pallavicini [protección].

Luna Oviedo, Katherinee con Ilustre Municipalidad de San Javier (2020): CS, 23 junio 2020 (Rol No 39182-2019), 3a Sala. M: Sandoval, Vivanco, J. Muñoz; Al: Lagos, Pierry (r) [protección]. 
JB Solutions SpA con Dirección General de Aeronáutica Civil (2020): CS, 21 septiembre 2020 (Rol N 39586-2020), 3a Sala. M: S. Muñoz (d), Sandoval, Vivanco (d) (r); Al: Quintanilla, Munita [protección].

Comunidad Indígena Mateo Nahuelpán con Subsecretaría Bienes Nacionales Región Metropolitana (2020): CS, 1 diciembre 2020 (Rol No 19107-2019), 3a Sala. M: S. Muñoz (p) (r), Vivanco, Llanos, Mera; Al: Etcheberry [protección].

Servicio de Evaluación Ambiental con Ribba Álvarez, Germán (2020): CS, 28 diciembre 2020 (Rol N 43799-2020), 3a Sala. M: S. Muñoz, Sandoval (r), Vivanco, Al: Quintanilla, Pierry [casación].

4. Plazo de la Administración para ejercer potestad sancionatoria [9 casos]

Herrera Yáñez, Erick con Aguilar Belmar, Max (2020): CS, 20 enero 2020 (Rol № 22346-2019), 3a Sala. M: S. Muñoz, Sandoval (r), Vivanco; Al: Quintanilla, Etcheberry [protección].

Universidad de Chile con Superintendencia de Salud (2020): CS, 20 mayo 2020 (Rol $N^{\circ}$ 42797-2020), 3a Sala. M: S. Muñoz (p), Sandoval, Vivanco; Al: Munita (r), Quintanilla [apelación reclamación].

Universidad de Chile con Superintendencia de Salud (2020): CS, 28 julio 2020 (Rol N²132020), 3a Sala. M: S. Muñoz (p), Sandoval, Gómez (r), Zepeda; Al: Pallavicini (d) [apelación ilegalidad].

Clínica Alemana de Valdivia con Superintendencia de Salud (2020): CS, 17 agosto 2020 (Rol No 94925-2020), 3a Sala. M: S. Muñoz, Sandoval, Vivanco; Al: Quintanilla, Munita [s/r] [apelación reclamación].

Clínica Alemana con Superintendencia de Salud (2020): CS, 22 septiembre 2020 (Rol No 72002-2020), 3a Sala. M: S. Muñoz, Sandoval (r), Vivanco; Al: Quintanilla, Perry [apelación reclamación].

Ramírez Cardoen, Nicolás con Superintendencia de Valores y Seguros (2020): CS, 28 septiembre 2020 (Rol N²1054-2020), 3a Sala. M: S. Muñoz (p), Sandoval, Vivanco (r); Al: Quintanilla, Lagos (p) [casación].

Laboratorio Recalcine con Instituto de Salud Pública (2020): CS, 3 noviembre 2020 (Rol No 34105-2019), 3a Sala. M: Sandoval, Dahm (r), Vivanco (d); Al: Quintanilla, Pierry [casación].

Consejo de Defensa del Estado con Donoso Caro, Jorge (2020): CS, 10 noviembre 2020 (Rol N 19399-2019), 1ª Sala. M: Künsemüller, Maggi, Aránguiz; Al: Munita (r), Gómez [casación].

Peña Merino, Mauricio con Superintendencia de Valores y Seguros (2020): CS, 17 noviembre 2020 (Rol N 31578-2018), 3a Sala. M: S. Muñoz (p), Vivanco, J. Muñoz (r), Mera; Al: Gajardo [apelación ilegalidad].

5. Agotamiento de la vía administrativa e interrupción del plazo para ejercer posteriores recursos jurisdiccionales [3 casos]

Oyarzún Carrasco, Claudio con Merino Rojas, Víctor (2020): CS, 6 marzo 2020 (Rol No 19089-2019), $3^{a}$ Sala. M: S. Muñoz (p), Sandoval, J. Muñoz; Al: Lagos, Abuauad (r) [protección].

Jorquera Niño de Zepeda, Juan Eduardo con Ministerio de Obras Públicas, Dirección General de Aguas (2020): CS, 6 abril 2020 (Rol N 33663-2019), $3^{\text {a }}$ Sala. M: S. Muñoz, Prado, Vivanco; Al: Gómez, Barra (r) [casación].

Dote Cofré, Myriam con Municipalidad de La Pintana (2020): CS, 12 mayo 2020 (Rol No 662020), $3^{a}$ Sala. M: S. Muñoz (p), Sandoval, Vivanco (r), Llanos; Al: Lagos [protección].

\section{Conflictos al presentar recursos jurisdiccionales}

6. Plazo de prescripción de la acción de nulidad administrativa [1 caso]

Moya Candia, Estrella con Fisco de Chile (2020): CS, 28 mayo 2020 (Rol No 7410-2019), 3a

Sala. M: S. Muñoz (d), Sandoval, Repetto (r); Al: Quintanilla, Pierry (p) [casación]. 
7. Cómputo del plazo para presentar recursos jurisdiccionales contra actos administrativos [6 casos]

Televisión Nacional de Chile con Ministros de la Corte de Apelaciones de Santiago (2020): CS, 7 enero 2020 (Rol N²0896-2019), 3ª Sala. M: Sandoval, Aránguiz, Vivanco, Repetto, Biel (r) [queja].

Stand Off S.A. con Palacios Parra, José Manuel Augusto (2020): CS, 5 marzo 2020 (Rol No 19182-2018), $3^{a}$ Sala. M: S. Muñoz, Sandoval, Vivanco; Al: Quintanilla, Etcheberry (r) [casación].

Caltec SpA con Secretario Regional Ministerial de Salud de Antofagasta (2020): CS, 9 marzo 2020 (Rol N²5021-2018), 3ª Sala. M: S. Muñoz, Sandoval, Aránguiz (r), Vivanco; Al: Etcheberry [casación].

Antofagasta Minerals S.A. con Secretaría Regional Ministerial de Salud de Atacama (2020): CS, 8 junio 2020 (Rol N² 29791-2018), 3a Sala. M: S. Muñoz (r), Sandoval, Aránguiz, Vivanco; Al: Munita [casación].

Ortega González, Óscar Iván con Cristi Marfil, Óscar (2020): CS, 26 octubre 2020 (Rol No 129375-2020), $3^{a}$ Sala. M: S. Muñoz, Sandoval, Vivanco, Ravanales; Al: Pierry [s/r] [casación].

Enel Distribución Chile S.A. con Superintendencia de Electricidad y Combustibles (2020): CS, 1 diciembre 2020 (Rol No 138642-2020), $3^{\text {a }}$ Sala. M: S. Muñoz, Sandoval, Vivanco; Al: Pierry, Abuauad [s/r] [apelación reclamación].

\section{Prescripción de la acción indemnizatoria de responsabilidad [9 casos]}

Silva Pedrero, Gloria con Municipalidad de Recoleta (2020). CS, 20 enero 2020 (Rol $N^{\circ}$ 29648-2018). 3a Sala. M: S. Muñoz (p), Sandoval (r), Silva, Al: Quintanilla, Pallavicini [casación].

Collihuin Rosendo, Millavil y otros con Fisco de Chile (2020). CS, 6 marzo 2020 (Rol No 33827-2019). 3a Sala. M: S. Muñoz (p), Sandoval (p), Aránguiz, Vivanco, Llanos (r) [casación].

Alarcón Velásquez, Samuel con Fisco de Chile (2020). CS, 26 marzo 2020 (Rol N²8962019). 3a Sala. M: S. Muñoz (d), Sandoval (r), Aránguiz, Vivanco; Al: Pallavicini [casación]. Vergara Fuente, Alonso con Fisco (2020). CS, 2 abril 2020 (Rol No 33839-2019). 3a Sala. M: S. Muñoz (r) (d), Sandoval, Vivanco, Llanos, Zepeda [casación].

Meza Ruiz, Nora y otro con Servicio de Salud del Biobío (2020). CS, 15 abril 2020 (Rol $N^{\circ}$ 23145-2019). 3a Sala. M: Sandoval, Vivanco (r), Zepeda; Al: Lagos, Pallavicini [casación].

Araya Carreño, Rodrigo y otros con Fisco de Chile (2020). CS, 19 mayo 2020 (Rol No 25169-2019). 3a Sala. M: S. Muñoz (p), Sandoval (d), Vivanco (r), Llanos (d); Al: Barra [casación].

Arnaboldi Cáceres, Jorge con Municipalidad de Valdivia (2020). CS, 28 mayo 2020 (Rol No 16079-2019). 3a Sala. M: S. Muñoz (p), Vivanco (r), Repetto, Llanos (d); Al: Quintanilla [casación].

Pharmamedica Limitada con Servicio de Salud Concepción (2020). CS, 6 octubre 2020 (Rol No 69921-2020). 3a Sala. M: S. Muñoz (p), Sandoval, Vivanco, Llanos; Al: Quintanilla (r) [casación].

Gestión Ecológica de Residuos S.A. con Municipalidad de Huechuraba (2020). CS, 15 octubre 2020 (Rol N² 27522-2019). 3a Sala. M: S. Muñoz (p), Sandoval, Llanos (r); Al: Quintanilla (d), Pierry [casación].

9. Prescripción acción indemnizatoria de crímenes de lesa humanidad por agentes del Estado [11 casos]

Jarpa Ortiz, Leandro con Fisco de Chile (2020): CS, 20 enero 2020 (Rol Nº 23093-2019), 2 ${ }^{\text {a }}$ Sala. M: Künsemüller, Cisternas (r), A. Muñoz, Valderrama, Dahm [casación].

Mardones Mardones, José con Fisco de Chile (2020): CS, 22 enero 2020 (Rol N² 230942019), 2a Sala. M: Künsemüller, Brito, Valderrama; Al: Lagos (r) (d), Abuauad [casación]. 
San Martín Bustos, José con Fisco de Chile (2020): CS, 2 marzo 2020 (Rol N²9167-2019), 2a Sala. M: Künsemüller, Cisternas, A. Muñoz, Valderrama (r), Dahm [casación].

Programa Ley 19.123 y otros con Fisco de Chile (2020): CS, 9 marzo 2020 (Rol No 83982018), 2a Sala. M: Künsemüller (r) (p), Brito, Cisternas (d), Valderrama; Al: Abuauad (d) [casación].

Leiva Pasten, Pablo con Fisco de Chile (2020): CS, 10 marzo 2020 (Rol No 26023-2019), 2 Sala. M: Künsemüller, Cisternas, A. Muñoz, Valderrama (r), Dahm [casación].

Cevallos Jones, Edgar y otros con Fisco de Chile (2020): CS, 12 junio 2020 (Rol No 89482018), 2a Sala. M: Künsemüller (r), Brito, Cisternas, Valderrama; Al: Lagos (d) [casación].

Concha Gálvez, Juvencio con Fisco de Chile (2020): CS, 16 junio 2020 (Rol No 34111-2019), 2a Sala. M: Künsemüller (r), Dahm, Biel; Al: Munita, Gajardo [casación].

Programa Ley 19.123 con Pérez Sánchez, Nelson y otros (2020): CS, 23 junio 2020 (Rol No 15186-2018), 2a Sala. M: Künsemüller, Brito, Valderrama, J. Muñoz; Al: Etcheberry (r) [casación].

Programa Ley 19.123 y otros con Fisco de Chile y otros (2020): CS, 26 julio 2020 (Rol No 13097-2018), 2a Sala. M: Künsemüller, Brito, Valderrama (r), Dahm, Llanos [casación].

Programa Ley 19.123 y otros con Fisco de Chile (2020): CS, 31 agosto 2020 (Rol No 148472018), 2a Sala. M: Künsemüller, Brito (r), Valderrama, Dahm, Llanos [casación].

Guelet Vera, César con Fisco de Chile (2020): CS, 9 noviembre 2020 (Rol No 44407-2020), 2a Sala. M: Künsemüller, Brito, Valderrama, Dahm; Al: Gajardo (r) [casación].

\section{Legitimación activa para ejercer la acción de protección [61 casos]}

Rey González, Marcela con Superintendencia de Servicios Sanitarios (2020): CS, 25 febrero 2020 (Rol N 40757-2019), 3a Sala. M: S. Muñoz (p), Vivanco, Llanos (p), Mera; Al: Barra [s/r] [protección].

Partido Radical de Chile con Dirección Regional del Trabajo Metropolitana Oriente (2020): CS, 24 abril 2020 (Rol N³9660-2020), 3a Sala. M: S. Muñoz, Sandoval, Vivanco; Al: Quintanilla, Pallavicini [s/r] [protección].

Muñoz Díaz, Héctor con Secretaría Regional Ministerial de Salud V Región (2020): CS, 28 abril 2020 (Rol N³9655-2020), 3a Sala. M: S. Muñoz (d), Sandoval, Vivanco; Al: Pierry, Pallavicini [s/r] [protección].

Vidal Barría, Marisol con Mañalich Muxi, Jaime (2020): CS, 28 abril 2020 (Rol N 396522020), 3a Sala. M: S. Muñoz, Sandoval, Vivanco; Al: Pierry, Pallavicini [s/r] [protección].

Valenzuela Contreras, Luis con Ramírez Sánchez, Anely (2020): CS, 29 abril 2020 (Rol N 30339-2020), 3a Sala. M: S. Muñoz, Sandoval (r), Vivanco; Al: Quintanilla, Lagos [protección].

Pérez Debelli, José con Briones Rojas, Ignacio (2020): CS, 7 mayo 2020 (Rol N 438342020), 3a Sala. M: S. Muñoz, Sandoval, Vivanco; Al: Quintanilla, Pallavicini [s/r] [protección].

Scaff Vega, Carmen con Ministerio de Hacienda (2020): CS, 11 mayo 2020 (Rol N 440712020), 3a Sala. M: S. Muñoz, Sandoval, Vivanco; Al: Etcheberry, Pierry [s/r] [protección].

Scaff Vega, Carmen con Ministerio de Hacienda (2020): CS, 11 mayo 2020 (Rol № 444282020), 3a Sala. M: S. Muñoz, Sandoval, Vivanco; Al: Etcheberry, Pierry [s/r] [protección].

Lobos Castro, Lorena con Briones Rojas, Ignacio (2020): CS, 11 mayo 2020 (Rol N 440672020), 3a Sala. M: S. Muñoz, Sandoval, Vivanco; Al: Etcheberry, Pierry [s/r] [protección].

Municipalidad de Caldera con Cross-Media SpA (2020): CS, 13 mayo 2020 (Rol No 251282019), 3a Sala. M: S. Muñoz, Sandoval, Aránguiz (r), Vivanco; Al: Pallavicini [protección].

Asociación Funcionarios Comisión Mercado Financiero con Comisión para el Mercado Financiero (2020): CS, 14 mayo 2020 (Rol N 44034-2020), 3a Sala. M: S. Muñoz, Sandoval, Vivanco; Al: Quintanilla, Lagos [s/r] [protección].

Federación Nacional Coordinadora de Bases de la Salud Pública con Subsecretaría de Redes Asistenciales (2020): CS, 14 mayo 2020 (Rol No 44120-2020), 3a Sala. M: S. Muñoz, Sandoval, Vivanco; Al: Quintanilla, Lagos [s/r] [protección]. 
Almonacid Soto, Yessica con Briones Rojas, Ignacio (2020): CS, 14 mayo 2020 (Rol N 44426-2020), 3a Sala. M: S. Muñoz, Sandoval, Vivanco; Al: Quintanilla, Lagos [s/r] [protección].

Gonzalez Galleguillos, Freddy con Ministerio de Hacienda (2020): CS, 14 mayo 2020 (Rol N 50386-2020), 3a Sala. M: S. Muñoz, Sandoval, Vivanco; Al: Quintanilla, Lagos [s/r] [protección].

Scaff Vega, Carmen con Ministerio de Hacienda (2020): CS, 14 mayo 2020 (Rol № 503892020), 3 a Sala. M: S. Muñoz, Sandoval, Vivanco; Al: Quintanilla, Lagos [s/r] [protección].

Barudy Labrín, Claudio con Recondo Lavanderos, Carlos (2020): CS, 20 mayo 2020 (Rol No 44137-2020), 3a Sala. M: S. Muñoz, Sandoval, Vivanco; Al: Quintanilla, Munita [s/r] [protección].

Confederación Nacional de Profesionales Universitarios de los Servicios de Salud con Subsecretaría de Redes Asistencias (2020): CS, 20 mayo 2020 (Rol N 43560-2020), 3a Sala. M: S. Muñoz, Sandoval, Vivanco; Al: Quintanilla, Munita [s/r] [protección].

Municipalidad de Padre Las Casas con Piñera Echeñique, Sebastián (2020): CS, 20 mayo 2020 (Rol N 50377-2020), 3a Sala. M: S. Muñoz, Sandoval, Vivanco; Al: Quintanilla, Munita [s/r] [protección].

Universidad de Valparaíso con Mañalich Muxi, Jaime (2020): CS, 20 mayo 2020 (Rol No33412-2020), 3a Sala. M: S. Muñoz, Sandoval, Vivanco; Al: Quintanilla, Munita [s/r] [protección].

Cristi Olmos, Maritza con Briones Rojas, Ignacio (2020): CS, 20 mayo 2020 (Rol Nº 50572 2020), 3a Sala. M: S. Muñoz, Sandoval, Vivanco; Al: Quintanilla, Munita [s/r] [protección].

Confederación Democrática de Profesionales Universitarios de la Salud con Mañalich Muxi, Jaime (2020): CS, 20 mayo 2020 (Rol N 42832-2020), 3a Sala. M: S. Muñoz, Sandoval, Vivanco; Al: Quintanilla, Munita [s/r] [protección].

Pezo Correa, Carlo con Briones Rojas, Ignacio (2020): CS, 20 mayo 2020 (Rol Nº 506132020), 3a Sala. M: S. Muñoz, Sandoval, Vivanco; Al: Quintanilla, Munita [s/r] [protección].

Caballero Vergara, Fabián con Jordán Lapostol, Camila (2020): CS, 20 mayo 2020 (Rol No 50736-2020), 3a Sala. M: S. Muñoz, Sandoval, Vivanco; Al: Quintanilla, Munita [s/r] [protección].

Ilustre Municipalidad de Cerro Navia con Mañalich Muxi, Jaime (2020): CS, 20 mayo 2020 (Rol No 42840-2020), 3a Sala. M: S. Muñoz, Sandoval, Vivanco; Al: Quintanilla, Munita [s/r] [protección].

Muñoz García, Patricia con Agencia Nacional de Inteligencia (2020): CS, 25 mayo 2020 (Rol $N^{\circ}$ 50571-2020), 3a Sala. M: S. Muñoz, Sandoval, Vivanco; Al: Quintanilla, Pallavicini [s/r] [protección].

Rebolledo Pizarro, Reginaldo con Ricotti Velásquez, Carlos (2020): CS, 27 mayo 2020 (Rol No 50714-2020), 3a Sala. M: S. Muñoz, Sandoval, Vivanco; Al: Gómez, Abuauad [s/r] [protección].

Ilustre Municipalidad de Lumaco con Piñera Echeñique, Sebastián (2020): CS, 27 mayo 2020 (Rol N 50699-2020), 3a Sala. M: S. Muñoz, Sandoval, Vivanco; Al: Gómez, Abuauad [s/r] [protección].

Sindicato Nacional del Instituto Profesional AIEP con Instituto Profesional AIEP S.A (2020): CS, 27 mayo 2020 (Rol No 50713-2020), 3a Sala. M: S. Muñoz, Sandoval, Vivanco; Al: Gómez, Abuauad [s/r] [protección].

Cristi Olmos, Maritza con Gaete Somarriva, Adriana (2020): CS, 27 mayo 2020 (Rol N 50717-2020), 3a Sala. M: S. Muñoz, Sandoval, Vivanco; Al: Gómez, Abuauad [s/r] [protección].

Ortega Berríos, Mauricio con Ministerio de Hacienda (2020): CS, 27 mayo 2020 (Rol No 50703-2020), 3a Sala. M: S. Muñoz, Sandoval, Vivanco; Al: Gómez, Abuauad [s/r] [protección].

Asociación de Funcionarios de la Dirección del Servicio de Salud Central con Mañalich Muxi, Jaime (2020): CS, 27 mayo 2020 (Rol N 50732-2020), 3a Sala. M: S. Muñoz, Sandoval, Vivanco; Al: Gómez, Abuauad [s/r] [protección]. 
Corporación Nacional de Consumidores y Usuarios Asociación de Consumidores con Isapre Banmédica S.A. (2020): CS, 27 mayo 2020 (Rol N 50737-2020), 3a Sala. M: S. Muñoz, Sandoval, Vivanco; Al: Gómez, Abuauad [s/r] [protección].

Federación Metropolitana de Funcionarios de la Salud con Blumel Mac-Iver Gonzalo (2020): CS, 27 mayo 2020 (Rol N 58488-2020), 3a Sala. M: S. Muñoz, Sandoval, Vivanco; Al: Gómez, Lagos [s/r] [protección].

Cerda Adaro, Patricio con Briones Rojas, Ignacio (2020): CS, 27 mayo 2020 (Rol № 58490 2020), 3a Sala. M: S. Muñoz, Sandoval, Vivanco; Al: Gómez, Lagos [s/r] [protección].

Confederación Democrática de Profesionales Universitarios de la Salud con Ministerio del Interior (2020): CS, 27 mayo 2020 (Rol N 58491-2020), 3a Sala. M: S. Muñoz, Sandoval, Vivanco; Al: Gómez, Lagos [s/r] [protección].

Asociación Nacional de Funcionarios del Ministerio de Educación con Ministerio de Hacienda (2020): CS, 27 mayo 2020 (Rol N 58504-2020), 3a Sala. M: S. Muñoz, Sandoval, Vivanco; Al: Gómez, Lagos [s/r] [protección].

Hirsch Goldschmidt, Tomás con Briones Rojas, Ignacio (2020): CS, 27 mayo 2020 (Rol No 58505-2020), 3a Sala. M: S. Muñoz (d), Sandoval, Vivanco; Al: Gómez, Lagos [s/r] [protección].

Sindicato Nacional No 1 de Trabajadores de la Fundación Integra con Ministerio de Educación (2020): CS, 27 mayo 2020 (Rol N 58524-2020), 3a Sala. M: S. Muñoz, Sandoval, Vivanco; Al: Gómez, Abuauad [s/r] [protección].

Muñoz Díaz, Héctor con Secretaría Regional Ministerial de Salud I Región (2020): CS, 28 mayo 2020 (Rol No 50527-2020), 3a Sala. M: S. Muñoz, Sandoval, Vivanco; Al: Lagos, Pallavicini [s/r] [protección].

Instituto Nacional de Derechos Humanos y otros con Gendarmería de Chile (2020): CS, 28 mayo 2020 (Rol No 58541-2020), 3a Sala. M: S. Muñoz, Sandoval, Vivanco; Al: Lagos, Pallavicini [s/r] [protección].

Barría Ailef, Patricio con Olivares Pemjean, Arturo (2020): CS, 3 junio 2020 (Rol Nº 598472020), 3a Sala. M: S. Muñoz, Sandoval, Vivanco; Al: Lagos, Pierry [s/r] [protección].

García de la Pastora Zavala, Reynerio con Dirección General Movilización Nacional (2020), 3 junio 2020 (Rol N 59858-2020), 3a Sala. M: S. Muñoz, Sandoval, Vivanco; Al: Lagos, Pierry [s/r] [protección].

Acevedo Menanteau, Paulina con Ricotti Velásquez, Carlos (2020): CS, 10 junio 2020 (Rol No 62992-2020), 3a Sala. M: S. Muñoz, Sandoval, Vivanco; Al: Pierry, Pallavicini [s/r] [protección].

Junta de Vecinos $N^{\circ}$ de Alto del Carmen con Heyermann Ríos, Enrique (2020): CS, 10 junio 2020 (Rol N 62993-2020), 3a Sala. M: S. Muñoz, Sandoval, Vivanco; Al: Pierry, Pallavicini [s/r] [protección].

Peña Muñoz, Paula con Junta Nacional de Jardines Infantiles (JUNJI) Regional (2020): CS, 10 junio 2020 (Rol N 63146-2020), 3a Sala. M: S. Muñoz, Sandoval, Vivanco; Al: Pierry, Pallavicini [s/r] [protección].

Asociación de Profesionales y Técnicos Universitarios de Fonasa con Fondo Nacional de Salud (2020): CS, 17 junio 2020 (Rol No 69668-2020), 3a Sala. M: S. Muñoz (d), Sandoval, Dahm, Vivanco; Al: Pierry [s/r] [protección].

Municipalidad de Los Álamos con Recicladora Muñoz y Cía. Limitada y otros (2020): CS, 19 junio 2020 (Rol N 44066-2020), 3a Sala. M: S. Muñoz (r), Sandoval, Vivanco; Al: Quintanilla, Lagos [protección].

Sindicato de Empresa Unidos Super Diez S.A. con Super 10 S.A. (2020): CS, 24 julio 2020 (Rol N 76610-2020), 3a Sala. M: S. Muñoz, Sandoval, Vivanco; Al: Quintanilla, Pallavicini [s/r] [protección].

Asociación de Administrativos, Auxiliares, Técnicos y Profesionales de la Junta Nacional de Jardines Infantiles con Junta Nacional de Jardines Infantiles (2020): CS, 3 agosto 2020 (Rol No 69748-2020), 3a Sala. M: S. Muñoz, Sandoval (r), Vivanco (p); Al: Pierry, Pallavicini (p) [protección]. 
Acevedo Menanteau, Paulina con 5ta. Comisaría Carabineros Puerto Montt (2020): CS, 14 agosto 2020 (Rol No 92162-2020), 3a Sala. M: S. Muñoz, Sandoval, Vivanco, Zepeda; Al: Pierry [s/r] [protección].

Castillo Castillo, Juan con Gallart Gabas, Antonio (2020): CS, 20 agosto 2020 (Rol No 94802-2020), 3a Sala. M: S. Muñoz, Sandoval, Vivanco; Al: Pierry, Pallavicini [s/r] [protección].

Fries Monleon, Julia con Carabineros (2020): CS, 25 agosto 2020 (Rol No 50743-2020), 3a Sala. M: S. Muñoz (r), Sandoval, Vivanco; Al: Lagos, Pierry [protección].

Confederación Nacional de Funcionarias y Funcionarios de Salud Municipal con Subsecretaría de Redes Asistenciales (2020): CS, 27 agosto 2020 (Rol No 88362-2020), 3a Sala. M: Sandoval, Vivanco, Repetto; Al: Quintanilla, Pallavicini [s/r] [protección].

Moya Navarrete, Rodrigo con Reyes Villagra, Leonardo (2020): CS, 27 agosto 2020 (Rol No 83668-2020), 3a Sala. M: Sandoval, Vivanco, Repetto; Al: Quintanilla, Pallavicini [s/r] [protección].

Asociación Gremial de Comerciantes de Productos del Mar A.G. con Sociedad Administradora del Terminal Pesquero S.A (2020): CS, 27 agosto 2020 (Rol N 79061-2020), 3a Sala. M: Sandoval, Vivanco, Repetto; Al: Quintanilla, Pallavicini [s/r] [protección].

Delgado Carrillo, Oriana con Escárate Peters, Raúl (2020): CS, 11 septiembre 2020 (Rol N² 27621-2019), 3a Sala. M: Sandoval, Vivanco, J. Muñoz; Al: Lagos (r), Pierry [protección].

Asociación de Enfermeras y Enfermeros Hospital Dr. Juan Noe Crevani de Arica con Servicio de Salud Arica (2020): CS, 14 septiembre 2020 (Rol No 72003-2020), 3a Sala. M: S. Muñoz, Sandoval, Vivanco (r) (p), Llanos (p), Zepeda (p) [protección].

Troncoso Gavilán, Magaly con Gendarmería de Chile (2020): CS, 23 septiembre 2020 (Rol No 112379-2020), 3a Sala. M: Sandoval, Dahm, Vivanco; Al: Quintanilla, Pierry [s/r] [protección].

Carreño Arias, Jenny con Guzmán Cepeda, José (2020): CS, 22 octubre 2020 (Rol $N^{\circ}$ 127300-2020), 3a Sala. M: S. Muñoz, Sandoval, Vivanco, Ravanales; Al: Pierry [s/r] [protección].

Federación de Asociaciones de Profesionales Técnicos de las Universidades del Estado de Chile con Ministerio de Educación (2020): CS, 22 octubre 2020 (Rol No 127204-2020), $3^{a}$ Sala. M: S. Muñoz, Sandoval, Vivanco, Ravanales; Al: Pierry [s/r] [protección].

Neira Grandón, Camila con Mericq Guila, Patricio (2020): CS, 29 diciembre 2020 (Rol № 55422020), 3a Sala. M: S. Muñoz (r) (d), Sandoval, Vivanco, Llanos; Al: Pierry [protección].

11. Procedencia y alcance de la acción de mera certeza [no se registraron casos en 2020]

III. Conflictos relativos a la estabilidad de los trabajadores en la administración

12. Funcionarios a honorarios y supletoriedad Código del Trabajo [28 casos]

Maldonado Roco, Paola Beatriz con Municipalidad de La Pintana (2020): CS, 3 enero 2020 (Rol No 15615-2019), $4^{\text {a }}$ Sala. M: Blanco, Chevesich (d), A. Muñoz, M. Silva, Repetto [s/r] [unificación de jurisprudencia laboral].

Tabilo Rodríguez, Mauro Leandro con Fisco de Chile (2020): CS, 31 enero 2020 (Rol No 16707-2019), 4a Sala. M: Blanco, Chevesich (d), Repetto; Al: Munita, Pallavicini [s/r] [unificación de jurisprudencia laboral].

Valdebenito Díaz, María Cristina con Fisco de Chile (2020): CS, 31 enero 2020 (Rol $N^{\circ}$ 18660-2019), $4^{a}$ Sala. M: Blanco, Chevesich (d), Repetto; Al: Munita, Pallavicini [s/r] [unificación de jurisprudencia laboral].

Carrasco Flores, Solange Victoria con Instituto Nacional de Deportes (2020): CS, 6 febrero 2020 (Rol 15678-2019), 4ª Sala. M: Blanco, Chevesich (d), A. Muñoz, Repetto; Al: De la Maza [s/r] [unificación de jurisprudencia laboral]. 
Tapia Jarpa, Nilsa Viviana con Municipalidad de Padre Hurtado (2020): CS, 7 febrero 2020 (Rol No 10621-2019), $4^{a}$ Sala. M: Blanco, M. Silva, Repetto; Al: Quintanilla, Lagos [s/r] [unificación de jurisprudencia laboral].

Aravena Aguilera, Génesis con Municipalidad de El Bosque (2020): CS, 7 febrero 2020 (Rol No 18161-2019), $4^{a}$ Sala. M: Blanco, M. Silva, Repetto; Al: Lagos, Pallavicini [s/r] [unificación de jurisprudencia laboral].

Ayancán Galindo, Daniela Alejandra con Fisco de Chile (2020): CS, 7 febrero 2020 (Rol No 19285-2019), 4 a Sala. M: Blanco, M. Silva, Repetto; Al: Lagos, Pallavicini [s/r] [unificación de jurisprudencia laboral].

Palomera Gómez, Matías Esteban con Municipalidad de Maipú (2020): CS, 27 febrero 2020 (Rol No 18538-2019), 4ª Sala. M: Blanco, Chevesich (d), A. Muñoz, M. Silva (p), Repetto [s/r] [unificación de jurisprudencia laboral].

Álvarez Barría, Viviana con Junta Nacional de Jardines Infantiles (2020): CS, 2 marzo 2020 (Rol No 15696-2019), 4ª Sala. M: Blanco, A. Muñoz, Repetto; Al: Etcheberry, Barra [s/r] [unificación de jurisprudencia laboral].

Pérez Vidal, Raúl Leonardo con Subsecretaría de Transporte (2020): CS, 2 de marzo 2020 (Rol No 18539-2019), 4ª Sala. M: Blanco, Chevesich (d), A. Muñoz, M. Silva (p), Repetto [s/r] [unificación de jurisprudencia laboral].

Guistini González, Giovanna Antonella con Corporación Nacional de Desarrollo Indígena (2020): CS, 11 marzo 2020 (Rol N 6247-2019), $4^{a}$ Sala. M: Blanco, Chevesich (d), M. Silva (p); Al: Munita, Barra [s/r] [unificación de jurisprudencia laboral].

Naguil Silva, Víctor Miguel con Municipalidad de San Juan de la Costa (2020): CS, 30 marzo 2020 (Rol No 14139-2019), 4ª Sala. M: Blanco, Chevesich (p), M. Silva; Al: Barra, De la Maza [s/r] [unificación de jurisprudencia laboral].

Carrasco Novoa, Víctor Manuel con Municipalidad de Recoleta (2020): CS, 6 junio 2020 (Rol N²2272-2019), 4a Sala. M: Blanco, A. Muñoz (d), M. Silva, Zepeda; Al: Etcheberry (d) [s/r] [unificación de jurisprudencia laboral].

Poblete Paredes, Jaime Darío con Servicio Nacional de Capacitación y Empleo (2020): CS, 12 junio 2020 (Rol No 23063-2019), $4^{a}$ Sala. M: Blanco, A. Muñoz, M. Silva, Zepeda; Al: De la Maza [s/r] [unificación de jurisprudencia].

Jerez Cancino, Karina Fabiola con Municipalidad de Maipú (2020): CS, 12 junio 2020 (Rol No 11896-2019), 4a Sala. M: S. Muñoz (d), Aránguiz, A. Muñoz, Vivanco; Al: Barra [s/r] [unificación de jurisprudencia laboral].

Valdés Contreras, Pablo con Municipalidad de Casablanca (2020): CS, 1 julio 2020 (Rol $N^{\circ}$ 22878-2019), $4^{a}$ Sala. M: Brito, Blanco, M. Silva, Llanos, J. Muñoz [s/r] [unificación de jurisprudencia laboral].

Pinto Carreño, Pamela Alejandra con Fisco de Chile (2020): CS, 17 julio 2020 (Rol $N^{\circ}$ 27650-2019), 4a Sala. M: Blanco, M. Silva (d), J. Muñoz (d); Al: Etcheberry, Barra [s/r] [unificación de jurisprudencia laboral].

Cerda Videla, María Inés con Fisco de Chile (2020): CS, 17 julio 2020 (Rol N²5988-2019), $4^{a}$ Sala. M: Blanco, A. Muñoz, M. Silva (p), Repetto; Al: Etcheberry [s/r] [unificación de jurisprudencia laboral].

Aldana Latorre, Juan con Servicio de Vivienda y Urbanismo V Región (2020): CS, 27 julio 2020 (Rol N²2872-2019), 4ª Sala. M: Brito, Blanco, A. Muñoz, M. Silva (p); Al: Barra [s/r] [unificación de jurisprudencia laboral].

Vargas Vargas, Felipe Arturo con Servicio Nacional del Adulto Mayor (2020): CS, 30 julio 2020 (Rol N² 29033-2019), 4a Sala. M: Blanco, A. Muñoz, M. Silva, Repetto; Al: De la Maza [s/r] [unificación de jurisprudencia laboral].

Corrial Zúñiga, Carla Andrea con Municipalidad de Maipú (2020): CS, 3 agosto 2020 (Rol N² 27854-2019), $4^{a}$ Sala. M: Blanco, A. Muñoz, M. Silva (p), Repetto; Al: De la Maza [s/r] [unificación de jurisprudencia laboral].

Carrillo Alvarado, Marianela con Fisco de Chile (2020): CS, 25 agosto 2020 (Rol No 296862019), $4^{a}$ Sala. M: Blanco, A. Muñoz, M. Silva (p), Repetto; Al: Etcheberry [s/r] [unificación de jurisprudencia laboral]. 
Utreras Barrales, Sergio con Municipalidad de Arica (2020): CS, 11 septiembre 2020 (Rol No 29599-2019), $4^{a}$ Sala. M: Blanco, A. Muñoz, M. Silva; Al: Etcheberry, De la Maza [s/r] [unificación de jurisprudencia laboral].

Espinoza Rojas, Jaime Eduardo con Municipalidad de Punta Arenas (2020): CS, 14 septiembre 2020 (Rol No 10523-2019), $4^{\text {a }}$ Sala. M: Blanco, A. Muñoz, M. Silva (p), Repetto (p); Al: Etcheberry [s/r] [unificación de jurisprudencia laboral].

Contardo Huidobro, María Cecilia con Junta Nacional de Jardines Infantiles (2020): CS, 28 septiembre 2020 (Rol No 29360-2019), $4^{\text {a }}$ Sala. M: Blanco, A. Muñoz, M. Silva (p), Repetto; Al: Barra [s/r] [unificación de jurisprudencia laboral].

Orellana Hermosilla, Jorge con Ministerio de Bienes Nacionales (2020): CS, 12 noviembre 2020 (Rol N² 29164-2019), 4a Sala. M: M: Blanco, Chevesich (d), M. Silva (p), Repetto; Al: De la Maza [s/r] [unificación de jurisprudencia laboral].

Fuentes Valle, Sandra Socratina con Junta Nacional de Jardines Infantiles (2020): CS, 12 noviembre 2020 (Rol No 29351-2019), 4a Sala. M: M: Blanco, Chevesich (d), M. Silva (p), Repetto; Al: De la Maza [s/r] [unificación de jurisprudencia laboral].

Lepe Muñoz, Vitalina del Carmen con Municipalidad de Maipú (2020): CS, 16 diciembre 2020 (Rol No 22236-2019), 4 Sala. M: Blanco, Chevesich (p), A. Muñoz, Repetto, M. Silva (p) [s/r] [unificación de jurisprudencia laboral].

\section{Término anticipado de empleos a contrata [48 casos]}

Gutiérrez Melo, Pablo con Brucher Valenzuela, Hernán Guillermo (2020): CS, 8 enero 2020 (Rol No 19181-2019), 3a Sala. M: Sandoval, Aránguiz (d), Prado; Al: Lagos (r), Barra (d) [protección].

Garrido Abarzúa, Ingrid Helen con Intendencia Regional de la Araucanía (2020): CS, 13 enero 2020 (Rol No 19528-2019), 3ª Sala. M: Sandoval, Aránguiz (d), Prado (r); Al: Lagos, Barra (d) [protección].

Villalobos Fleming, Andrea con Servicio Nacional de Menores (2020): CS, 14 enero 2020 (Rol N²0119-2019), $3^{\text {a }}$ Sala. M: S. Muñoz, Sandoval, Aránguiz (r); Al: Quintanilla, Pierry (d) [protección].

Aravena Monardes, Wilfredo Germán con Subsecretaría de Prevención del Delito del Ministerio del Interior y Seguridad Pública (2020): CS, 23 enero 2020 (Rol No 26142-2019), $3^{\text {a }}$ Sala. M: S. Muñoz (p), Sandoval (d), Prado; Al: Quintanilla, Pallavicini (d) (r) [protección].

Miranda Álvarez, Nina con Subsecretaría de Servicios Sociales (2020): CS, 28 enero 2020 (Rol N²6194-2019), $3^{\text {a }}$ Sala. M: S. Muñoz (d), Sandoval, Prado; Al: Quintanilla, Pallavicini (d) (r) [protección].

Mundaca Barraza, Andrés con Junta Nacional de Auxilio Escolar y Becas (2020): CS, 3 febrero 2020 (Rol No 25684-2019), 3a Sala. M: S. Muñoz (p), Sandoval (d), Vivanco; Al: Lagos (r), Gómez [protección].

Díaz Guajardo, Pablo Mauricio con Junta Nacional de Jardines Infantiles (2020): CS, 3 febrero 2020 (Rol N²7760-2019), 3ª Sala. M: S. Muñoz (p) (r), Vivanco, J. Muñoz; Al: Quintanilla, Pallavicini (d) [protección].

Bravo Quezada, Carmen con Universidad de Santiago (2020): CS, 3 febrero 2020 (Rol No 27756-2019), $3^{\text {a }}$ Sala. M: S. Muñoz, Vivanco, J. Muñoz; Al: Quintanilla, Pallavicini (d) [protección].

Bautista Menares, David Gustavo con Martorell Awad, Katherine (2020): CS, 3 febrero 2020 (Rol No 26956-2019), $3^{a}$ Sala. M: S. Muñoz (p), Vivanco, Biel (p); Al: Munita (r), Barra [protección].

Insunza Carvajal, Susana con Secretaría Regional Ministerial de Bienes Nacionales de Antofagasta (2020): CS, 3 febrero 2020 (Rol N² 27583-2019), $3^{\text {a }}$ Sala. M: S. Muñoz (p), Vivanco, Biel (p); Al: Munita (r), Barra [protección].

Aedo Cerda, María Magdalena con López Castillo, Mario Francisco (2020): CS, 3 febrero 2020 (Rol No 22956-2019), 3a Sala. M: S. Muñoz (p), Sandoval (d), Vivanco (p); Al: Lagos (r), Gómez [protección]. 
Lobos Suazo, Rolando Patricio con Servicio de Registro Civil e Identificación Santiago (2020): CS, 10 febrero 2020 (Rol No 29270-2019), 3a Sala. M: S. Muñoz (p), Sandoval (d), Vivanco, J. Muñoz; Al: Pallavicini (d) (r) [protección].

Ormeño Vilches, Carlos con Secretaría Regional Ministerial de Salud de la Región de la Araucanía (2020): CS, 10 febrero 2020 (Rol N² 27017-2019), $3^{\text {a }}$ Sala. M: S. Muñoz (d), Aránguiz (d), Vivanco; Al: Pierry, Pallavicini (r) [protección].

Aránguiz Cabrera, Luis Hernán con Agencia de Calidad de la Educación (2020): CS, 20 febrero 2020 (Rol No 28831-2019), $3^{a}$ Sala. M: S. Muñoz (p), Vivanco (r), J. Muñoz; Al: Quintanilla, Pierry (d) [protección].

Lüttecke Bórquez, Lorena Beatriz con Junta Nacional de Auxilio Escolar y Becas (2020): CS, 20 febrero 2020 (Rol N² 28820-2019), $3^{\text {a }}$ Sala. M: M: S. Muñoz (p), Vivanco (r), J. Muñoz; Al: Quintanilla, Pierry (d) [protección].

Ramírez Krause, Claudia Violeta con Ministerio del Deporte (2020): CS, 20 febrero 2020 (Rol N² 28828-2019), $3^{a}$ Sala. M: M: S. Muñoz (p), Vivanco (r), J. Muñoz; Al: Quintanilla, Pierry (d) [protección].

Mateluna Estay, Rodrigo Andrés con Servicio Nacional del Consumidor (2020): CS, 4 marzo 2020 (Rol N² 29208-2019), 3a Sala. M: S. Muñoz (p), Sandoval (d), Vivanco, J. Muñoz; Al: Pallavicini (d) (r) [protección].

Mercado Acevedo, Rodrigo Angelo de Jesús con Domínguez Covarrubias, José (2020): CS, 4 marzo 2020 (Rol No 29297-2019), 3ª Sala. M: S. Muñoz (p), Sandoval (d), Vivanco, J. Muñoz; Al: Pallavicini (d) (r) [protección].

Salgado Miranda, Julio Antonio con Ministerio de Salud (2020): CS, 4 marzo 2020 (Rol No 26085-2019), $3^{a}$ Sala. M: S. Muñoz, Sandoval, Prado; Al: Quintanilla, Pallavicini (d) (r) [protección].

Navarrete Pradenas, Sergio Esteban con Ministerio del Interior y Seguridad Pública (2020): CS, 23 marzo 2020 (Rol N²4900-2020), $3^{\text {a }}$ Sala. M: S. Muñoz, Sandoval, Vivanco, Llanos; Al: Pallavicini (d) [s/r] [protección].

Franjola Espinoza, Scarlett Ivonne con Junta Nacional de Jardines Infantiles (2020): CS, 30 marzo 2020 (Rol N²9829-2019), $3^{a}$ Sala. M: S. Muñoz, Sandoval (r), Aránguiz, Vivanco; Al: Pallavicini (d) [protección].

Soto Cuevas, Roxana con Hospital Regional de Rancagua (2020): CS, 31 marzo 2020 (Rol No 30609-2020), $3^{\text {a }}$ Sala. M: S. Muñoz (d), Sandoval, Vivanco, Llanos (d); Al: Pallavicini [s/r] [protección].

Valdenegro Mebark, Salomón con Junta Nacional de Jardines Infantiles (2020): CS, 3 abril 2020 (Rol N 38866-2019), $3^{a}$ Sala. M: S. Muñoz (p) (r), Llanos, Zepeda; Al: Quintanilla, Barra [protección].

Williams Ibáñez, Mary con Subsecretaría del Interior (2020): CS, 3 abril 2020 (Rol № 362062019), $3^{a}$ Sala. M: S. Muñoz, Vivanco (d), Repetto, Llanos; Al: Quintanilla (d) (r) [protección].

Cáceres Rivera, Diego Alejandro con Contraloría General de la República (2020): CS, 3 abril 2020 (Rol No 38853-2019), 3ª Sala. M: S. Muñoz (r), Llanos, Zepeda; Al: Barra, QuintaniIla (p) (r) [protección].

Miranda Delgado, Alejandra con Instituto Nacional del Deporte (2020): CS, 3 abril 2020 (Rol N³3317-2019), $3^{\text {a }}$ Sala. M: Aránguiz, Llanos, Zepeda (r); Al: Quintanilla (d), Pallavicini (d) [protección].

Ruiz Ovando, María Soledad con Servicio Nacional para la Prevención y Rehabilitación del Consumo de Drogas y Alcohol (2020): CS, 3 abril 2020 (Rol N 38634-2019), $3^{\text {a }}$ Sala. M: S. Muñoz (p) (r), Llanos, Zepeda; Al: Quintanilla, Barra [protección].

Toledo Gutiérrez, María Teresa con Instituto de Salud Pública (2020): CS, 3 abril 2020 (Rol N 2914-2020), $3^{a}$ Sala. M: S. Muñoz (p) (r), Sandoval (d), Vivanco, Llanos; Al: Pierry (d) [protección].

Concha Castillo, Francisco Javier con Subsecretaría de Bienes Nacionales de la Región de la Araucanía (2020): CS, 8 abril 2020 (Rol N 30271-2020), 3a Sala. M: S. Muñoz (p), Sandoval (d), Vivanco, Llanos (p); Al: Pallavicini (d) (r) [protección]. 
Mena Díaz, Leopoldo Nicolás con Ministerio de Desarrollo Social (2020): CS, 15 abril 2020 (Rol N³6244-2019), $3^{\text {a }}$ Sala. M: S. Muñoz (p), Vivanco, Repetto, Llanos; Al: Quintanilla (r) [protección].

Zumelzu Standen, Ivy Gay Elizabeth con Carabineros de Chile (2020): CS, 17 abril 2020 (Rol $N^{\circ}$ 24463-2020), $3^{\text {a }}$ Sala. M: S. Muñoz (p), Sandoval, Vivanco (r), Llanos; Al: Etcheberry [protección].

Suazo González, Héctor con Servicio de Registro Civil e Identificación (2020): CS, 24 abril 2020 (Rol N² 21161-2020), 3a Sala. M: Sandoval, Vivanco, Llanos; Al: Lagos (r), Pallavicini (d) [protección].

Medel Farías, Andrés Leonardo con Servicio de Registro Civil e Identificación (2020): CS, 30 abril 2020 (Rol N²9837-2019), 3ª Sala. M: S. Muñoz, Sandoval (d), Aránguiz (r), Vivanco, Llanos [protección].

Galleguillos Véliz, Marco Antonio con Domínguez Covarrubias, José Luis Francisco (2020): CS, 6 mayo 2020 (Rol No 14915-2020), $3^{a}$ Sala. M: S. Muñoz, Vivanco, Llanos; Al: Pierry (d), Pallavicini (d) (r) [protección].

Bustos Salgado, Francisco con Fisco de Chile (2020): CS, 6 mayo 2020 (Rol N 388902019), $3^{a}$ Sala. M: S. Muñoz, Llanos, Gómez, Zepeda; Al: Pierry (d) (r) [protección].

Mallea Araus, Pilar con Superintendencia de Educación (2020): CS, 18 mayo 2020 (Rol $N^{\circ}$ 52-2020), $3^{\text {a }}$ Sala. M: S. Muñoz (r), Sandoval (d), Zepeda; Al: Etcheberry (p), Pallavicini (d) [protección].

García Avendaño, Paola con Oficina Nacional de Emergencias (2020): CS, 25 mayo 2020 (Rol N 50738-2020), $3^{\text {a }}$ Sala. M: S. Muñoz, Sandoval, Vivanco; Al: Quintanilla, Pallavicini (d) [s/r] [protección].

Araya Ibacache, Patricio con Subsecretaría de Prevención del Delito (2020): CS, 30 junio 2020 (Rol N 33379-2019), 3ª Sala. M: S. Muñoz, Sandoval (d), Gómez, Zepeda (r); Al: Pallavicini (d) [protección].

Santos Ramos, Patricia con Fisco de Chile (2020): CS, 21 agosto 2020 (Rol No 92148-2020),

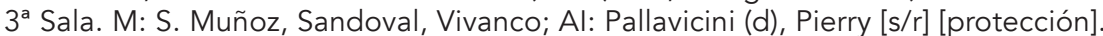

Smirnov Berríos, Raúl con II Contraloría Regional Metropolitana de Santiago (2020): CS, 16 septiembre 2020 (Rol N² 24856-2020), $3^{\text {a }}$ Sala. M: S. Muñoz (d), Sandoval, Vivanco; Al: Lagos, Etcheberry (r) [protección].

Quezada Hernández, Nibaldo Julián con Servicio Nacional de Menores (2020): CS, 24 septiembre 2020 (Rol N²7619-2020), 3ª Sala. M: S. Muñoz, Sandoval (d), Vivanco, Llanos (r); Al: Pallavicini (d) [protección].

Vargas Saldivia, José con Ministerio de Hacienda (2020): CS, 1 octubre 2020 (Rol No 69938 2020), $3^{a}$ Sala. M: S. Muñoz (p) (r), Sandoval (d), Vivanco; Al: Pierry (p), Pallavicini (d) [protección].

Caruncho Franco, Pamela con Universidad Tecnológica Metropolitana (2020): CS, 5 octubre 2020 (Rol No 94887-2020), 3a Sala. M: Sandoval, Vivanco, Repetto (d); Al: Quintanilla (d) (r), Pallavicini [protección].

Inostroza Naranjo, Karin con Municipalidad de Quinta Normal (2020): CS, 24 noviembre 2020 (Rol No 138312-2020), $3^{\text {a }}$ Sala. M: S. Muñoz (d), Sandoval, Vivanco, Ravanales; Al: Quintanilla [s/r] [protección].

Peralta Gutiérrez, Daniela Amaia con Carabineros de Chile (2020): CS, 26 noviembre 2020 (Rol N 122293-2020), $3^{\text {a }}$ Sala. M: S. Muñoz (p), Sandoval (d) (r), Vivanco, Biel; Al: Quintanilla [protección].

Klinowski Gómez, David José con Universidad de Santiago de Chile (2020): CS, 1 diciembre 2020 (Rol N 119275-2020), 3a Sala. M: S. Muñoz, Sandoval (d), Vivanco; Al: Pierry, Abuauad [s/r] [protección].

Chirkova, Serafima con Universidad de Santiago de Chile (2020): CS, 1 diciembre 2020 (Rol $\left.N^{\circ} 119262-2020\right), 3^{a}$ Sala. M: S. Muñoz, Sandoval (d), Vivanco; Al: Pierry, Abuauad [s/r] [protección].

Castañeda González, Francisco Enrique con Universidad de Santiago de Chile (2020): CS, 21 diciembre 2020 (Rol No 112869-2020), $3^{a}$ Sala. M: Sandoval, Vivanco (p), Biel (r); Al: Quintanilla, Abuauad (p) [protección]. 
14. Desviación de poder en las desvinculaciones de funcionarios a contrata [4 casos]

Gálvez Villella, Gonzalo con Municipalidad de La Cruz (2020): CS, 25 junio 2020 (Rol 320792019), $3^{a}$ Sala. M: Llanos, Sandoval, Vivanco; Al: Lagos, Pallavicini (r) [protección].

Castillo Gajardo, Luis con Municipalidad de La Pintana (2020): CS, 9 septiembre 2020 (Rol 63005-2020), $3^{a}$ Sala. M: S. Muñoz (p), Sandoval, Vivanco; Al: Pallavicini (d) (r), Pierry [protección].

Gómez Esquivel, Juan con Municipalidad de la Pintana (2020): CS, 9 septiembre 2020 (Rol 63092-2020), $3^{a}$ Sala. M: S. Muñoz, Sandoval, Vivanco; Al: Pallavicini (d) (r), Pierry [protección].

Müller Contreras, Héctor con Municipalidad de Chaitén (2020): CS, 27 octubre 2020 (Rol 27678-2019), $3^{a}$ Sala. M: Llanos, S. Muñoz, Zepeda; Al: Barra, Quintanilla (r) [protección].

15. Recurso de protección como vía idónea en casos de desvinculación de funcionarios a contrata [117 casos]

Concha Galaz, Patricia con Ministerio de Educación y Secretaría Regional Ministerial de Educación de la Región del Biobío (2020): CS, 6 enero 2020 (Rol No 19981-2019), 3a Sala. M: Aránguiz (d), Dahm (r), Sandoval; Al: Barra (d), Munita [protección].

Gutiérrez Melo, Pabla con Brucher Valenzuela, Hernán (2020): CS, 8 enero 2020 (Rol N 19181-2019) 3a Sala, M: Aránguiz (d), Prado, Sandoval; Al: Barra (d), Lagos (r) [protección].

Garrido, Ingrid con Intendencia Regional de la Araucanía (2020): CS, 13 enero 2020 (Rol No 19528-2019) $3^{a}$ Sala. M: Aránguiz (d), Prado (r), Sandoval; Al: Barra (d), Lagos [protección].

Villalobos Fleming, Andrea con Servicio Nacional de Menores (2020): CS, 14 enero 2020 (Rol N²0119-2019), 3ª Sala. M: S. Muñoz, Sandoval, Aránguiz (r); Al: Quintanilla, Pierry (d) [protección].

Morales Caro, Teresa con Ministerio de Educación (2020): CS, 15 enero 2020 (Rol No 19980-2019), 3a Sala. M: Aránguiz (d), Dahm, Sandoval; Al: Barra (d), Munita (r) [protección].

Vera Monroy, Sebastián con Ministerio de Educación (2020): CS, 17 enero 2020 (Rol No 24035-2019), $3^{a}$ Sala. M: S. Muñoz (r), Sandoval (d), Mena; Al: Barra, Etcheberry [protección]

Vivanco Vivanco, Cecilia con Escarate Peters, Raúl (2020): CS, 17 enero 2020 (Rol $N^{\circ}$ 24134-2019), $3^{a}$ Sala. M: S. Muñoz (r) (d), Sandoval, Mera; Al: Barra, Etcheberry [protección].

Herrera Yáñez, Erick con Aguilar Belman, Max (2020): CS, 20 enero 2020 (Rol № 223462019), $3^{a}$ Sala. M: S. Muñoz, Sandoval (r), Vivanco; Al: Etcheberry, Quintanilla [protección].

Aravena Monardes, Wilfred con Subsecretaría de Prevención del Delito y Ministerio del Interior (2020): CS, 23 enero 2020 (Rol N²6142-2019) 3a Sala. M: S. Muñoz (p) Prado, Sandoval (d); Al: Pallavicini (d)(r) Quintanilla [protección].

Miranda Delgado, Alejandra con Subsecretaria de Servicios Sociales y Ministerio de Desarrollo Social (2020): CS, 28 enero 2020 (Rol N²6194-2019) $3^{\text {a }}$ Sala. M: S. Muñoz, Prado, Sandoval; Al: Pallavicini (d) (r), Quintanilla [protección].

Aedo Cerda, María con López Castillo, Francisco y Quezada Fonseca, Mario (2020): CS, 3 febrero 2020 (Rol N²2956-2019) 3ª Sala. M: S. Muñoz (p), Sandoval (d), Vivanco (p); Al: Gómez, Lagos (r) [protección].

Bautista Menares, David con Martorell Awad, Katherine (2020): CS, 3 febrero 2020 (Rol $N^{\circ}$ 26956-2019), $3^{a}$ Sala. M: S. Muñoz (p), Vivanco, Biel (p); Al: Barra, Munita (r) [protección].

Bravo Quezada, Carmen con Universidad de Santiago de Chile (2020): CS, 3 febrero 2020 (Rol No 27756-2019), $3^{\text {a }}$ Sala. M: S. Muñoz (r), Vivanco, J. Muñoz; Al: Pallavicini (d) Quintanilla [protección]. 
Díaz Gajardo, Pablo con Junta Nacional de Jardines Infantiles de la Región del Maule (2020): CS, 3 febrero 2020 (Rol No 27760-2019), 3a Sala. M: S. Muñoz (r), Vivanco, J. Muñoz; Al: Pallavicini (d), Quintanilla [protección].

Inzunza Carvajal, Susana con Secretaría Regional Ministerial del Ministerio de Bienes Nacionales Región de Antofagasta (2020): CS, 3 febrero 2020 (Rol N² 27583-2019), $3^{\text {a }}$ Sala. M: S. Muñoz (p), Vivanco, Biel (p); Al: Barra, Munita (r) [protección].

Mora Fritz, Francisco con Servicio de Vivienda y Urbanismo Metropolitano (2020): CS, 3 febrero 2020 (Rol N²2323-2019), $3^{a}$ Sala. M: S. Muñoz, Sandoval, Vivanco; Al: Gómez, Lagos (r) [protección].

Mundaca Barraza, Andrés con Junta Nacional de Auxilio Escolar y Becas (2020): CS, 3 febrero 2020 (Rol N²5684-2019), 3a Sala. M: S. Muñoz (p), Sandoval (d), Vivanco; Al: Lagos (r), Gómez [protección].

Díaz Navarrete, Mario con Ministerio del Deporte (2020): CS, 10 febrero 2020 (Rol No 13713 -2019), $3^{a}$ Sala. M: S. Muñoz (d) (r), Sandoval, Vivanco; Al: Munita, Quintanilla [protección].

Lobos Suazo, Rolando con Servicio de Registro Civil e Identificación (2020): CS, 10 febrero 2020 (Rol N² 29270-2019), $3^{a}$ Sala. M: S. Muñoz, Sandoval (d), Vivanco, J. Muñoz; Al: Pallavicini (r) (d) [protección].

Ormeño con Secretaría Regional Ministerial de Salud de la Región de la Araucanía (2020): CS, 10 febrero 2020 (Rol N² 27017-2019), 3ª Sala. M: Aránguiz (d) S. Muñoz (d) Vivanco; Al: Pallavicini, Pierry [s/r] [protección].

Lovera Ojeda, Claudio con Ministerio de Obras Públicas (2020): CS, 18 febrero 2020 (Rol No 22135-2019), $3^{a}$ Sala, M: Aránguiz (d), S. Muñoz (d), Sandoval, Vivanco (r); Al: Pallavicini [protección].

Aránguiz Cabrera, Luis con Agencia de Calidad de la Educación (2020): CS, 20 febrero 2020 (Rol N²8831-2019), $3^{\text {a }}$ Sala. M: S. Muñoz (p), Vivanco (r), J. Muñoz; Al: QuintaniIla, Pierry (d) [protección].

Lüttecke Bórquez, Lorena con Junta Nacional de Auxilio Escolar y Becas (2020): CS, 20 febrero 2020 (Rol No 28820-2019), 3ª Sala. M: S. Muñoz (p), Vivanco (r), J. Muñoz; Al: Quintanilla, Pierry (d) [protección].

Mascayano O'Ryen,, Rafael con Servicio de Salud Metropolitano Central (2020): CS, 20 febrero 2020 (Rol No 28836-2019), 3ª Sala. M: S. Muñoz (d), Vivanco (r), J. Muñoz; Al: Pierry, Quintanilla [protección].

Ramírez Krauze, Claudia con Ministerio del Deporte (2020): CS, 20 febrero 2020 (Rol No 28828-2019), $3^{\text {a }}$ Sala. M: S. Muñoz, Vivanco (r), J. Muñoz; Al: Pierry (d), Quintanilla [protección].

Chales de Beaulieu Stetcher, Jorge con Gobierno Regional Metropolitano de Santiago (2020): CS, 21 febrero 2020 (Rol N²8857-2019), 3a Sala. M: S. Muñoz, Vivanco (r), J. Muñoz; Al: Pierry (d), Quintanilla (d) [protección].

Comene Matamoros, Margaret con Ministerio del Trabajo y Previsión Social (2020): CS, 26 febrero 2020 (Rol N² 26248-2019), $3^{\text {a }}$ Sala. M: S. Muñoz (d), Prado (p), Sandoval; Al: PaIlavicini, Quintanilla (d) [s/r] [protección].

Leal Condeza, Elizabeth con Junta Nacional de Jardines Infantiles (2020): CS, 2 marzo 2020 (Rol No 18823-2019), 3ª Sala. M: Aránguiz, S. Muñoz, Sandoval, Vivanco (r); Al: Quintanilla [protección].

Ulloa Cifuentes, Paulo con Servicio de Registro Civil e Identificación (2020): CS, 3 marzo 2020 (Rol N²2316-2019), 3ª Sala. M: Aránguiz, S. Muñoz, Sandoval (d), Vivanco (r); Al: Quintanilla (d) [protección].

Valenzuela Faúndez, Jaime, con Secretaría Regional Ministerial Ministerio de Desarrollo Social del Maule (2020): CS, 3 marzo 2020 (Rol No 12589-2019), $3^{a}$ Sala. M: Aránguiz, S. Muñoz, Sandoval (r), Vivanco; Al: Quintanilla [protección].

Salgado Miranda, Julio con Ministerio de Salud (2020). CS, 4 marzo 2020 (Rol N²60852019), $3^{a}$ Sala. M: S. Muñoz, Prado, Sandoval; Al: Pallavicini (d) (r) Quintanilla [protección]. 
Roa Gutiérrez, Marisa con Contraloría General de la República (2020): CS, 5 marzo 2020 (Rol N 31831-2019), $3^{\text {a }}$ Sala. M: Aránguiz, Llanos (r), Zepeda; Al: Etcheberry, QuintaniIla [protección].

Carmona Berrios, Mauricio con Ministerio Secretaria General de Gobierno (2020): CS, 23 marzo 2020 (Rol N 24901-2019) $3^{\text {a }}$ Sala. M: Llanos, S. Muñoz, Sandoval (d) Vivanco; Al: Pallavicini (d) [s/r] [protección].

Navarrete Pradenas, Sergio con Ministerio del Interior (2020): CS, 23 marzo 2020 (Rol $N^{\circ}$ 24900-2020), $3^{a}$ Sala. M: Llanos, S. Muñoz, Sandoval, Vivanco; Al: Pallavicini (d) [s/r] [protección].

Franjola Espinoza, Scarlett con Junta Nacional de Jardines Infantiles (2020): CS, 30 marzo 2020 (Rol N² 29829-2019), 3ª Sala. M: Aránguiz, S. Muñoz, Sandoval (r), Vivanco; Al: PaIlavicini (d) [protección].

Soto Fuentes, Jaime con Gobernación Provincial de Malleco (2020): CS, 30 marzo 2020 (Rol No 31495-2019), $3^{a}$ Sala. M: Dahm, Sandoval, Vivanco; Al: Lagos (r), Pierry [protección].

Cortés Fernández, Paula con Instituto Nacional de Estadísticas (2020): CS, 3 abril 2020 (Rol N 36562-2019), $3^{a}$ Sala. M: Llanos, S. Muñoz, Repetto, Vivanco; Al: Quintanilla (r) [protección].

Díaz Yáñez, Esmeralda con Ministerio de Desarrollo Social (2020): CS, 3 abril 2020 (Rol $N^{\circ}$ 2719-2020), 3a Sala. M: Llanos (r)(d), S. Muñoz, Sandoval, Vivanco; Al: Pierry [protección].

Henríquez Allendes, Nicolás con Ministerio de Vivienda y Urbanismo (2020): CS, 3 abril 2020 (Rol N 11107-2020), 3a Sala. M: Llanos (d), S. Muñoz (d), Sandoval, Vivanco; Al: Pierry [s/r] [protección].

Lagos Devia, Marta y Sandoval Bustamante, Lynn, con Municipalidad de la Pintana (2020): CS, 3 abril 2020 (Rol N 30723-2020), $3^{\text {a }}$ Sala. M: S. Muñoz (d), Sandoval, Vivanco; Al: Lagos, Munita [s/r] [protección].

Lara González, Patricia con Ministerio del Interior (2020): CS, 3 abril 2020 (Rol № 1618-2020), $3^{a}$ Sala, M: Llanos, S. Muñoz (p) (r) Sandoval (d) Vivanco; Al: Pierry (d) [protección].

Mancilla Ureta, Manuel con Servicio de Registro Civil e Identificación (2020): CS, 3 abril 2020 (Rol N 38-2020), $3^{a}$ Sala. M: Llanos, S. Muñoz (r) (p) Sandoval (d), Vivanco; Al: Pierry (d) [protección].

Ruiz Ovando, María con Servicio Nacional para la Prevención y Rehabilitación del Consumo de Drogas y Alcohol (2020): CS, 3 abril 2020 (Rol N 38634-2019), $3^{\text {a }}$ Sala. M: Llanos, S. Muñoz ( $r$ ) (p), Zepeda; Al: Barra, Quintanilla [protección].

Seguel Neira, Samuel con Servicio de Salud de Arica (2020): CS, 3 abril 2020 (Rol $N^{\circ}$ 11106-2020), $3^{a}$ Sala. M: Llanos, S. Muñoz (p) (r), Vivanco, Sandoval (d); Al: Pierry (d) [protección].

Toledo Gutiérrez, María con Instituto de Previsión Social (2020): CS, 3 abril 2020 (Rol No 2914-2020), $3^{a}$ Sala, M: Llanos, S. Muñoz (r)(p), Vivanco, Sandoval (d); Al: Pierry (d) [protección].

Williams Ibáñez, Mary con Subsecretaría del Interior (2020): CS, 3 abril 2020 (Rol N 36206-2019), $3^{a}$ Sala. M: Llanos, S. Muñoz, Repetto, Vivanco (d); Al: Quintanilla (r) (d) [protección].

Mella Pérez, Ernesto con Servicio de Salud Región de Arica (2020): CS, 7 abril 2020 (Rol N²3260-2020), $3^{a}$ Sala. M: Aránguiz, S. Muñoz (d), Sandoval, Silva, Vivanco [s/r] [protección].

Ortega González, Max con Dirección General de Aguas (2020): CS, 7 abril 2020 (Rol No 36556-2019), $3^{\text {a }}$ Sala, M: Llanos, S. Muñoz, Repetto, Vivanco; Al: Quintanilla (r) [protección].

Rojas González, Romina con Instituto de Previsión Social (2020): CS, 7 abril 2020 (Rol No 30248-2020), 3a Sala. M: S. Muñoz (d), Sandoval, Vivanco; Al: Pierry, Quintanilla [s/r] [protección].

Concha Castillo, Francisco con Ministerio de Bienes Nacionales (2020): CS, 8 abril 2020 (Rol No 30271-2020), $3^{a}$ Sala, M: Llanos (p), S. Muñoz (p), Sandoval (d), Vivanco; Al: PaIlavicini (r) (d) [protección]. 
Opazo Arriagada, Miguel con Servicio Médico Legal (2020): CS, 8 abril 2020 (Rol №302632020) $3^{a}$ Sala. M: Llanos, S. Muñoz, Sandoval, Vivanco; Al: Pallavicini (r) (d) [protección].

Arguello Garzón, Jorge con Hospital Clínico Herminda San Martín (2020): CS, 13 abril 2020 (Rol N 14714-2020), $3^{\text {a }}$ Sala. M: Llanos, S. Muñoz, Sandoval (d), Vivanco; Al: Pallavicini (r) (d) [protección].

Fuentes Aranda, Ingrid con Junta Nacional de Jardines Infantiles (2020): CS, 13 abril 2020 (Rol N²1107-2020), 3a Sala. M: Llanos (d), S. Muñoz (d) (r), Sandoval, Vivanco; Al: Etcheberry [protección].

Acuña Prat, Paulina con Ministerio de Justicia y Derechos Humanos (2020): CS, 15 abril 2020 (Rol No 36210-2020), 3ª Sala. M: Llanos, S. Muñoz, Repetto, Vivanco; Al: QuintaniIla (r) [protección].

Mena Diaz, Leonardo con Ministerio de Desarrollo Social y Familia (2020): CS, 15 abril 2020 (Rol No 36244-2020), $3^{a}$ Sala. M: Llanos, S. Muñoz (p), Repetto, Vivanco; Al: Quintanilla (r) [protección].

Loayza Lizana, Javier, con Universidad de Aysén (2020): CS, 16 abril 2020 (Rol № 395132020), $3^{\text {a }}$ Sala. M: S. Muñoz (d), Sandoval, Vivanco; Al: Pallavicini, Pierry [s/r] [protección].

Zumelzu Standen, Ivy con Carabineros de Chile (2020): CS, 17 abril 2020 (Rol No 24463-

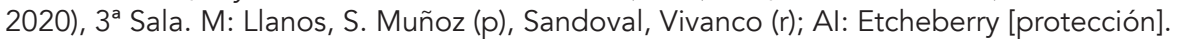

Suazo González, Héctor con Servicio de Registro Civil e Identificación Región de Aysén (2020): CS, 24 abril 2020 (Rol No 21161-2020), $3^{\text {a }}$ Sala. M: Llanos (r), Sandoval, Vivanco; Al: Lagos, Pallavicini (d) [protección].

Del Valle Palma, Carlos con Servicio de Salud Nuble (2020): CS, 29 abril 2020 (Rol N²7593-2020), $3^{a}$ Sala. M: Llanos (d), S. Muñoz (d), Sandoval (r) Vivanco; Al: Pallavicini [protección].

Ríos Aramayo, Rodrigo con Universidad de La Serena (2020): CS, 29 abril 2020 (Rol $N^{\circ}$ 18881-2020), $3^{a}$ Sala. M: Llanos, S. Muñoz, Sandoval (d), Vivanco (r); Al: Pallavicini (d) [protección].

López Molina, María con Tesorería General de la República (2020): CS, 30 abril 2020 (Rol No 33628-2019), $3^{a}$ Sala. M: S. Muñoz, Sandoval, Gómez; Al: Pierry, Quintanilla (r) [protección].

Medel Farías, Andrés con Servicio de Registro Civil e Identificación (2020): CS, 30 abril 2020 (Rol N² 29837-2020), 3ª Sala. M: Aránguiz (r)(p), Llanos, S. Muñoz (p), Sandoval (d), Vivanco [protección].

Astudillo Ibaceta, Claudia con Tesorería General de la República (2020): CS, 4 mayo 2020 (Rol N 38867-2019), $3^{\text {a }}$ Sala. M: Llanos, S. Muñoz (r)(p), Zepeda; Al: Barra, Quintanilla [protección].

García Huerta, Berenice con Consejo de Defensa del Estado (2020): CS, 4 mayo 2020 (Rol $N^{\circ}$ 14815-2020), $3^{\text {a }}$ Sala. M: Llanos (d), S. Muñoz (d), Sandoval, Vivanco (r), J. Muñoz. [protección].

Mena Rivas, Nathalie con Tesorería General de la República (2020): CS, 4 mayo 2020 (Rol No 38864-2019), $3^{a}$ Sala. M: Llanos, S. Muñoz (r) (p), Zepeda; Al: Barra, Quintanilla [protección].

Galleguillos Véliz, Marco con Ministerio de Transporte y Telecomunicaciones (2020): CS, 6 mayo 2020 (Rol No 14915-2020), 3a Sala. M: Llanos, S. Muñoz, Vivanco; Al: Pallavicini (r) (d), Pierry (d) [protección].

Stull Acosta, Ingrid con Contraloría General de la República (2020): CS, 6 mayo 2020 (Rol No 38888-2019), 3a Sala. M: S. Muñoz (p), Sandoval (r) (d), Vivanco, Zepeda; Al: Etcheberry [protección].

Tiffou Valencia, Augusto con Servicio Nacional de Aduanas (2020): CS, 6 mayo 2020 (Rol No 33767-2019), $3^{a}$ Sala. M: S. Muñoz, Sandoval (d), Gómez, Zepeda (r); Al: Pallavicini [protección].

Figueroa Vega, Carlos, con Municipalidad de Curicó (2020): CS, 13 mayo 2020 (Rol No 1624-2020), $3^{a}$ Sala. M: Llanos (r), S. Muñoz, Sandoval (d), Vivanco; Al: Lagos [protección]. 
García Fuentes, Yenine con Municipalidad de Conchalí (2020): CS, 13 mayo 2020 (Rol $N^{\circ}$ 30-2020), $3^{\text {a }}$ Sala. M: S. Muñoz (d), Sandoval, Vivanco (r), Zepeda (d); Al: Etcheberry [protección].

Cea Novoa, Daniel con Municipalidad de Purén (2020): CS, 15 mayo 2020 (Rol N 437892020), $3^{a}$ Sala. M: S. Muñoz, Sandoval, Vivanco; Al: Lagos, Pallavicini (d) [s/r] [protección].

Lorca Zúñiga, Karina con Gobierno Regional de O'Higgins (2020): CS, 15 mayo 2020 (Rol $N^{\circ}$ 14823-2020), $3^{\text {a }}$ Sala. M: Llanos (d), S. Muñoz (d), Sandoval, Vivanco, J. Muñoz [s/r] [protección].

Mallea Araus, Pilar con Superintendencia de Educación (2020): CS, 18 mayo 2020 (Rol $N^{\circ}$ 52-2020), $3^{\text {a }}$ Sala. M: S. Muñoz (r), Sandoval; (d), Zepeda; Al: Etcheberry (p), Pallavicini (d) [protección].

Gallegos Parra, Carlos con Servicio de Salud de Chiloé (2020): CS, 20 mayo 2020 (Rol No 44430-2020), $3^{a}$ Sala. M: S. Muñoz, Sandoval, Vivanco; Al: Quintanilla, Munita [s/r] [protección].

García Avendaño, Paola con Oficina Nacional de Emergencias (2020): CS, 25 mayo 2020 (Rol N 50738-2020), $3^{\text {a }}$ Sala. M: S. Muñoz, Sandoval, Vivanco; Al: Pallavicini (d), Quintanilla [s/r] [protección].

Gutiérrez Herrera, Rodrigo con Junta Nacional de Jardines Infantiles (2020): CS, 25 mayo 2020 (Rol N 50731-2020), $3^{\text {a }}$ Sala. M: S. Muñoz (d), Sandoval, Vivanco; Al: Pallavicini, Quintanilla [s/r] [protección].

Ibarra Reyes, Javier con Instituto Nacional de Desarrollo Agropecuario (2020): CS, 25 mayo 2020 (Rol N 58520-2020), 3a Sala. M: S. Muñoz (d), Sandoval, Vivanco; Al: Pallavicini, Quintanilla [s/r] [protección].

Sazo Pradenas, Marcelo con Instituto Nacional de Estadísticas (2020): CS, 25 mayo 2020 (Rol N 50722-2020), $3^{a}$ Sala. M: S. Muñoz (d), Sandoval, Vivanco (d); Al: Quintanilla, Pallavicini [s/r] [protección].

Ibacache Onetto, Karla con Junta Nacional de Jardines Infantiles (2020): CS, 27 mayo 2020 (Rol N² 21101-2020), $3^{\text {a }}$ Sala. M: Llanos, S. Muñoz (r), Sandoval (d), Vivanco; Al: Etcheberry [protección].

Barahona García, Tomás con Gobierno Regional de O'Higgins (2020): CS, 1 junio 2020 (Rol $N^{\circ}$ 62657-2020), $3^{a}$ Sala. M: S. Muñoz (d), Sandoval, Vivanco; Al: Lagos, Quintanilla [s/r] [protección].

Blanco Balbontín, Stefano con Contraloría General de la República (2020): CS, 1 junio 2020 (Rol No 43963-2020), $3^{a}$ Sala. M: S. Muñoz (d), Sandoval, Vivanco; Al: Lagos, Quintanilla [s/r] [protección].

Moreno Huaiquinao, Génesis con Fisco de Chile (2020): CS, 5 junio 2020 (Rol N² 298692020), $3^{a}$ Sala. M: S. Muñoz (r) (p), Sandoval (d), Vivanco, Zepeda; Al: Etcheberry [protección].

Carmona Pérez, Susana con Secretaría Regional Ministerial de Salud Metropolitana (2020): CS, 8 junio 2020 (Rol No 63082-2020), 3a Sala. M: S. Muñoz, Sandoval, Vivanco; Al: Quintanilla, Pierry [s/r] [protección].

Baeza Vásquez, Mariangeles con Servicio de Registro Civil e Identificación (2020): CS, 10 junio 2020 (Rol No 43663-2020), 3ª Sala. M: S. Muñoz, Sandoval, Vivanco; Al: Etcheberry (r), Pierry [protección].

González Pradenas, Jaime con Ministerio de Transportes y Telecomunicaciones (2020): CS, 10 junio 2020 (Rol No 43571-2020), 3a Sala. M: S. Muñoz (d), Sandoval, Vivanco; Al: Etcheberry (r), Pierry [protección].

Lagos Astudillo, Rubén con Ministerio del Interior (2020): CS, 10 junio 2020 (Rol № 440182020), $3^{a}$ Sala. M: S. Muñoz, Sandoval, Vivanco; Al: Etcheberry (r), Pierry [protección].

Medina Silva, María con Ministerio de Medio Ambiente (2020): CS, 10 junio 2020 (Rol No 43835-2020),. $3^{\text {a }}$ Sala. M: S. Muñoz (d), Sandoval, Vivanco; Al: Etcheberry (r), Pierry [protección]. 
Momberg Vial, Roberto con Servicio de Salud de Reloncaví (2020): CS, 10 junio 2020 (Rol $N^{\circ}$ 43601-2020), $3^{a}$ Sala. M: S. Muñoz (d), Sandoval, Vivanco (d); Al: Etcheberry (r), Pierry [protección].

Cárdenas Andrade, Osvaldo con Junta Nacional de Jardines Infantiles (2020): CS, 12 junio 2020 (Rol N 36775-2019), 3a Sala. M: S. Muñoz (d), Sandoval, Gómez, Zepeda (d) (r); Al: Pallavicini [protección].

Llagostera Martines, Agustín con Universidad de Antofagasta (2020): CS, 19 junio 2020 (Rol $N^{\circ}$ 42343-2020), $3^{\text {a }}$ Sala. M: S. Muñoz (d), Sandoval, Vivanco (d); Al: Etcheberry (r), Pierry [protección].

Garrido Rojo, Carolina con Carabineros de Chile (2020): CS, 22 junio 2020 (Rol № $71954-$ 2020), $3^{a}$ Sala. M: S. Muñoz, Sandoval, Vivanco; Al: Abuauad, Gómez [s/r] [protección].

Quezada Quezada, Enrique con Municipalidad de Conchalí (2020): CS, 26 junio 2020 (Rol $N^{\circ}$ 44115-2020), 3a Sala. M: S. Muñoz, Sandoval, Vivanco; Al: Etcheberry (r), Pierry [protección].

Araya Ibacache, Patricio con Ministerio del Interior y Seguridad Pública (2020): CS, 30 junio 2020 (Rol N 33379-2019), $3^{a}$ Sala. M: S. Muñoz, Sandoval (d), Gómez, Zepeda (r); Al: Pallavicini (d) [protección].

González Negrete, Verónica con Municipalidad de Santiago (2020): CS, 14 julio 2020 (Rol $N^{\circ}$ 20788-2020), $3^{a}$ Sala. M: Llanos, Sandoval (r), Vivanco; Al: Lagos, Pallavicini [protección].

Nahuelpán Angulo, Victoria con Superintendencia del Medio Ambiente (2020): CS, 23 julio 2020 (Rol N 33287-2020), $3^{\text {a }}$ Sala. M: S. Muñoz, Sandoval (d), Vivanco (r); Al: Lagos, Quintanilla [protección].

Acevedo Troncoso, Karen con Corporación Administrativa del Poder Judicial (2020). CS, 24 julio 2020 (Rol No 79110-2020). 3a Sala. M: S. Muñoz, Vivanco, Zepeda; Al: Quintanilla (d), Pallavicini (d) [s/r] [protección].

Muñoz Arancibia, Elizabeth con Contraloría General de la República (2020): CS, 3 agosto 2020 (Rol No 71955-2020), 3a Sala. M: S. Muñoz (p), Sandoval (d), Vivanco; Al: Abuauad (r) (d), Gómez [protección].

Pérez Silva, Ana con Gobierno Regional Metropolitano de Santiago (2020): CS, 18 agosto 2020 (Rol No 76262-2020), $3^{a}$ Sala. M: S. Muñoz (r), Sandoval, Vivanco; Al: Lagos, Pierry [protección].

Santos Ramos, Patricia con Hospital de Carabineros Humberto Arriagada Valdivieso (2020): CS, 21 agosto 2020 (Rol No 92148-2020), $3^{\text {a }}$ Sala. M: S. Muñoz, Sandoval, Vivanco; Al: Pallavicini (d), Pierry [s/r] [protección].

Campaña González, Carmen con Instituto de Previsión Social (2020): CS, 25 agosto 2020 (Rol No 76739-2020), $3^{\text {a }}$ Sala. M: Sandoval (d), Vivanco, Zepeda (r); Al: Munita, Pierry (d) [protección].

Castillo Gajardo, Luis con Municipalidad de La Pintana (2020). CS, 9 septiembre 2020 (Rol No 63005-2020). $3^{\text {a }}$ Sala. M: S. Muñoz, Sandoval, Vivanco; Al: Pallavicini (d)(r), Pierry [protección].

Gómez Esquivel, Juan con Municipalidad de la Pintana (2020): CS, 9 septiembre 2020 (Rol No 63092-2020), $3^{\text {a }}$ Sala. M: S. Muñoz, Sandoval, Vivanco; Al: Pallavicini (d) (r), Pierry [protección].

Navea Castillo, Constanza con Servicio de Registro Civil e Identificación (2020): CS, 9 septiembre 2020 (Rol No 39585-2020), 3ª Sala. M: S. Muñoz, Sandoval (d), Vivanco; Al: Munita (r), Quintanilla [protección].

Leguá Molina, Fernando con Servicio Nacional de Menores (2020): CS, 24 septiembre 2020 (Rol N² 27606-2020), 3ª Sala. M: Llanos (r), S. Muñoz, Sandoval (d), Vivanco; Al: Pallavicini (d) [protección].

Quezada Hernández, Nibaldo con Servicio Nacional de Menores (2020): CS, 24 septiembre 2020 (Rol N² 27619-2020), 3a Sala. M: Llanos (r), S. Muñoz, Sandoval (d), Vivanco; Al: Pallavicini (d) [protección]. 
Vargas Saldivia, José con Ministerio de Hacienda (2020): CS, 1 octubre 2020 (Rol N 699382020), $3^{a}$ Sala. M: S. Muñoz (r) (p), Sandoval (d), Vivanco; Al: Pallavicini (d), Pierry (p) [protección].

Bunster Fuenzalida, Patricia y Pineda García, José con Instituto Nacional del Deporte (2020): CS, 6 octubre 2020 (Rol No 119308-2020), 3a Sala. M: S. Muñoz, Sandoval, Vivanco; Al: Lagos, Munita [s/r] [protección].

Campos Sepúlveda, Karla con Instituto de Previsión Social (2020): CS, 6 octubre 2020 (Rol No 119257-2020), $3^{\text {a }}$ Sala. M: S. Muñoz, Sandoval (d), Vivanco; Al: Lagos (d), Munita [s/r] [protección].

Bravo Díaz, Milenka con Ministerio de Obras Públicas (2020): CS, 27 octubre 2020 (Rol No 131067-2020), $3^{\text {a }}$ Sala. M: S. Muñoz, Sandoval (d), Ravanales, Vivanco; Al Quintanilla [s/r]. [protección].

Inostroza Naranjo, Karina con Municipalidad de Quinta Normal (2020): CS, 24 noviembre 2020 (Rol No 138312-2020), $3^{a}$ Sala, M: S. Muñoz (d), Sandoval, Vivanco, Ravanales; Al: Quintanilla [s/r] [protección].

Ruiz Vera, Carlos con Gendarmería de Chile (2020): CS, 24 noviembre 2020 (Rol $N^{\circ}$ 104239-2020), $3^{a}$ Sala. M: S. Muñoz, Sandoval, Vivanco, Ravanales (d); Al: QuintaniIla [s/r] [protección].

Peralta Gutiérrez, Daniela con Carabineros de Chile (2020): CS, 26 noviembre 2020 (Rol $N^{\circ}$ 122293-2020), $3^{a}$ Sala. M: Biel, S. Muñoz, Sandoval (r) (d), Vivanco; Al: Quintanilla [protección].

Arévalo Reyes, Rodolfo con Fuerza Aérea de Chile (2020): CS, 1 diciembre 2020 (Rol $N^{\circ}$ 139884-2020), $3^{a}$ Sala. M: S. Muñoz, Sandoval, Vivanco; Al: Abuauad, Pierry [s/r] [protección].

Chirkova, Serafima con Universidad de Santiago (2020): CS, 1 diciembre 2020 (Rol No 119262-2020), $3^{a}$ Sala. M: S. Muñoz, Sandoval (d), Vivanco; Al: Abuauad, Pierry [s/r] [protección].

Martínez Donoso, Karla con Hospital Dr. Ernesto Torres Galdames (2020): CS, 9 diciembre 2020 (Rol No 122199-2020), 3ª Sala. M: S. Muñoz, Vivanco (r), Sandoval (d); Al: Pallavicini (d), Quintanilla [protección].

Muñoz Lühr, Carolina con Dirección del Trabajo (2020): CS, 21 diciembre 2020 (Rol $N^{\circ}$ 88373-2020), $3^{a}$ Sala. M: S. Muñoz (p), Sandoval, Vivanco (r) (p); Al: Pallavicini (d), Pierry (d) [protección].

\section{Conflictos en recursos naturales, medio ambiente y bienes públicos}

16. Regularización de derechos de aguas [12 casos]

Flores Viza, Primitivo y otros con Agrícola Lluta S.A. (2020): CS, 29 enero 2020 (Rol No 11998-2019), 3a Sala. M: S. Muñoz, Vivanco, J. Muñoz; Al: Quintanilla (d), Pierry (r) (d) [casación]

Flores Viza, Primitivo y otros con Agrícola Lluta S.A. (2020): CS, 29 enero 2020 (Rol No 13907-2019), 3a Sala. M: S. Muñoz, Vivanco, J. Muñoz; Al: Quintanilla (d), Pierry (r) (d) [casación]

Flores Flores, Cipiana con Junta de Vigilancia del Rio Lluta y sus Tributarios (2020): CS, 12 febrero 2020 (Rol No 12990-2019), 3a Sala. M: S. Muñoz, Dahm, Prado (d) (r), Vivanco, J. Muñoz [casación]

Huanca Olave, Martín y otros con Dirección General de Aguas (2020): CS, 12 febrero 2020 (Rol No 14162-2019), 3a Sala. M: S. Muñoz, Dahm, Prado (d) (r), Vivanco, J. Muñoz [casación].

Huanca Olave, Martín y otros con Dirección General de Aguas (2020): CS, 12 febrero 2020 (Rol No 12988-2019), 3a Sala. M: S. Muñoz, Dahm, Prado (d) (r), Vivanco, J. Muñoz [casación].

Agrícola y Forestal Las Casas del Carmen S.A. con Empresa Nacional de Electricidad S.A., Sociedad Agrícola Viña Luis Felipe Edwards (2020): CS, 14 febrero 2020 (Rol № 311642018), 3a Sala. M: S. Muñoz, Vivanco, Biel; Al: Munita (r), Barra (d) [casación]. 
Parrao López, Gladys del Carmen con Junta de Vigilancia Estero Chimbarongo (2020): CS, 1 abril 2020 (Rol N²2976-2019), 3a Sala. M: S. Muñoz, Vivanco (r), Biel; Al: Pierry, Pallavicini [casación].

Meta Varlese, Luigi Rocco con Dirección General de Aguas Región de Valparaíso (2020): CS, 7 abril 2020 (Rol N 13850-2020), 3a Sala. M: S. Muñoz (d), Sandoval (r), Vivanco (d), Aránguiz, Llanos [casación].

Mulet, David Arturo con Dirección General de Aguas (2020): CS, 30 julio 2020 (Rol No 20931-2020), 3a Sala. M: S. Muñoz (r), Sandoval (d), Vivanco; Al: Lagos (d), Pallavicini [casación].

Comercial Greenwich S.A. con Dirección General de Aguas (2020): CS, 28 agosto 2020 (Rol No 1584-2020), 3a Sala. M: S. Muñoz (r), Vivanco, Llanos, Mera. Al: Etcheberry [casación].

González Rodríguez, Santiago y otros con Dirección General de Aguas y otros (2020): CS, 18 noviembre 2020 (Rol No 27495-2020), 3a Sala. M: S. Muñoz, Sandoval (d), Vivanco; Al: Quintanilla (d), Abuauad (r) [casación].

17. Autorizaciones administrativas como requisitos de servidumbres mineras [1 caso]

Muñoz Rodríguez, Juan Carlos con Fisco de Chile (2020): CS, 3 febrero 2020 (Rol N 5331 2018), 4a Sala. M: Blanco (d), Repetto (r), A. Muñoz, Chevesich; Al: De la Maza [casación].

18. Plazo para que tercero absoluto pueda solicitar invalidación ambiental [1 caso]

Stipicic Escauriaza, Ana Pilar con Director Ejecutivo Servicio Evaluación Ambiental (2020): CS, 12 marzo 2020 (Rol No 8737-2018), 3a Sala. M: S. Muñoz (d), Vivanco (d), Sandoval, Aránguiz, Prado (r) [casación].

19. Afectación presunta de bienes privados al uso público [no se registraron casos en 2020]

20. Acceso a playas públicas [no se registraron casos en 2020] 